\title{
A REVUELTAS CON LA STORYTELLING LLAMADA «PONDERACIÓN», Y TAMBIÉN PREGUNTANDO SOBRE «LIMITES» DEL DERECHO
}

\author{
Enrique P. Haba \\ Universidad de Costa Rica
}

RESUMEN. En ese debate, ambos contendores cultivan ciertas respectivas «novelas de conceptos", con base especialmente en puntos de vista tributarios de visiones ius-esencialistas: un esencialismo jurídico «razonabilista» frente a un esencialismo legalista. Así se conservan intactas también las enormes penumbras de vaguedades de ciertos conceptos fundamentales a que respectivamente recurre cada uno de aquéllos. Entonces quedan fuera de foco preguntas cruciales, señaladamente aquéllas del todo básicas que permitan examinar las cuestiones jurídicas en planos que se fijen sobre todo en la practicidad social real de las fórmulas discursivas utilizadas. Con ello el pensamiento se aleja de encarar esas cuestiones en términos capaces de someterlas a exigencias metodológicas - precisión intersubjetiva en el manejo de esos conceptos, aquilatamiento de facticidades sociales - aptas para resolver de la manera más adecuada posible, jen la práctica!, los conflictos que llegan a los tribunales. Especialmente se examinan esas cuestiones a propósito de ciertas postulaciones (esencialistas) en cuanto a unos supuestos «límites» netos del derecho y atribuyéndole a éste la condición (imaginaria) de constituir un sistema propiamente dicho. Por último, a tales modelos idealistas de discurso jurídico es contrapuesto aquí un posible modelo realista para los razonamientos judiciales, dirección de pensamiento orientada a poder sacar el máximo provecho de los conocimientos pertinentes suministrados por las ciencias sociales.

Palabras clave: ponderación, naturalismo lingüístico, «límites» del derecho, significados «posibles», esencialismo jurídico, realismo jurídico.

\section{Around and around the storytelling called «ponderación», and also asking about the «boundaries» of Law}

ABSTRACT. This paper is a critical commentary on a discussion about the judicial balancing of principles. There, both contenders have raised points of view based on some «novels of concepts», specifically two essentialist conceptions of the judicial discourse: a "rationalistic" law-essentialism vs. a legalistic essentialism. In this way, such approaches also maintain large penumbras of vagueness regarding certain fundamental concepts used by these scholars. Both lines of thinking avoid approaching law matters in a manner that would subject them to more accurate methodological requirements, i. e. through intersubjective specifications regarding those concepts and paying attention to the true social effects of judges' interpretative choices. Thereby, the very crucial questions remain generally out of focus: notably, the basic alternative issues that would make it possible to assess legal questions through more transparent modes of juridical reasoning, which will mainly highlight the real social effectiveness of the discursive formulas employed for juridical

* Fecha de recepción: 1 de julio de 2014. Fecha de aceptación: 22 de septiembre de 2014. 
purposes. Especially examined, are certain essentialist postulations which allege that law itself has net «limits» and confer lawyer's thinking the imaginary condition that it is properly a system. Lastly, such idealist approaches are here countered by a possible realist model for legal reasoning, which is apt to take best advantage of empirical knowledge provided by the social sciences.

Keywords: judicial balancing, word naturalism, «boundaries» of law, «possible» meaning, legal essentialism, legal realism. 
Those are my principles, and if you don't like them... well, I have others.

Groucho MARX

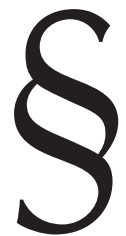

Querido Juan Antonio ${ }^{1}$ :

He leído íntegramente, y con toda atención (creo), el librito que tuviste la gentileza de mandarme: este debate, entre tú y Manolo, sobre eso que se denomina «ponderación» jurídica ${ }^{2}$. Me complace sobremanera ver que los aspectos tratados se encaran ahí con mucha riqueza de argumentos, por ambas partes; asimismo, lo cual es no menos recomendable, aprecio que cada uno no omite indicar, mediante oportunas citas y referencias precisas, a qué puntos específicos de lo señalado por el otro va aludiendo (a diferencia, pues, de lo acontecido en nuestro reciente debate sobre la argumentación jurídica) ${ }^{3}$. No puedo sino felicitarles por haber llevado adelante con tanta seriedad académica, y con tanto talento, esta discusión.

En efecto, he hallado múltiples motivos de interés en estos textos. Te ofrezco unas cuantas observaciones al respecto, para lo cual iré «espigando» por aquí y allá en lo puesto sobre el tapete ahí. Me concentraré en los aspectos siguientes:

1. Punto de partida («The Purple Rose of...»).

2. Preguntas cruciales soslayadas.

3. Palabras y «hechos» (y el asunto de las «pruebas»).

4. Indiferencia de hecho, para el razonamiento jurídico profesional, de la controversia cognitivismo/no-cognitivismo axiológicos. Dos «posturas» doctrinarias que, a fin de cuentas, están bastante «cerca» entre sí.

5. Disputa entre recomendaciones; recurso a unas distinciones inocuas. Fórmulas de falsa precisión. ¿Cuáles son los significados jurídicos «posibles»?

6. ¿Cómo conocer los «límites» del «derecho» positivo? [i]: dos maneras enfrentadas, pero idealistas ambas (storytelling), de concebirlos; y la metáfora de entender el derecho como una «empresa» (relativo acierto, pero también proclividad al misticismo, mediante esa imagen) .

7. El derecho como «empresa». Las interpretaciones de los juristas constituyen «apuestas» por hacer aceptar unos sentidos como necesariamente jurídicos.

8. ¿Cómo conocer los «límites» del «derecho» positivo? [ii]: naturalismo lingüístico y, con base en éste, la presuposición de que hay un «sistema» jurídico (...confiando en poder localizar esta otra cuadratura-del-círculo).

1 El presente comentario recoge (con cambios menores: incorpora los subtítulos y las notas subpaginales, también me consiento «pulir» detalles de redacción y ampliar un poco algunas explicaciones) el texto de mi Comentario para J. A. García Amado (12 de diciembre de 2012), enviado como correspondencia a él mismo.

2 M. Atienza Rodríguez y J. A. García Amado, Un debate sobre la ponderación, Lima-Bogotá, PalestraTemis (col. Pensamiento Jurídico Contemporáneo, núm. 11), 2012, 138 pp.

3 Me estoy tomando la libertad de aludir a la circunstancia de que, en dicha ocasión, ninguno de mis críticos consideró del caso indicar referencia específica alguna a pasajes concretos de mis propios escritos, para sustentar las objeciones que me fueron formuladas allí por parte de ellos [ese debate fue publicado en: Doxa, 33 (2010), 319-450; complementariamente, Revista Telemática de Filosofía del Derecho (www.rtfd.es), RTFD, núm. 14 (2011), 239-316. Los materiales de ambas publicaciones, precedidos de una introducción por M. ATIENZA y complementados por un estudio final de R. CARRIÓN WAM, se recogen en un libro que, con el mismo título de la discusión original, Debate sobre las teorías de la argumentación jurídica, está programado para publicarse (2014) en el sello editorial Palestra-Temis, Lima-Bogotá]. 
9. Fundamentales faltas de distinción entre los planos de enfoque. La impronta esencialista.

10. ¿Cómo conocer los «límites» del «derecho» positivo? [iii]: aproximación realista ante esa cuestión.

11. A modo de conclusión: presencia de unos elementos de realismo, pero secundarios y de configuración imprecisa, en medio de la pseudo-objetividad disimuladora en que consisten las sibilinas fórmulas llamadas «ponderación».

Tomaré así vuestros puntos de vista como pretexto para llamar la atención acerca de unas puntualizaciones de fondo básicas, las cuales no suelen aparecer sobre el tapete — ¡ni aun para ser cuestionadas! - en ninguna de las principales aproximaciones que hoy imperan para los estudios especializados conocidos específicamente como la disciplina particular llamada teoría del derecho.

\section{PUNTO DE PARTIDA ( «THE PURPLE ROSE OF...»)}

No te causará sorpresa, ni puede provocársela a Manolo, si reconozco que estoy muy de acuerdo con la gran mayoría de los señalamientos tuyos allí, cuya básica idea central (a mi juicio) se encuentra estupendamente bien explicada sobre todo en las pp. 40-52 de tu primera intervención, junto con unos cuantos otros pasajes de esta misma y también otros de la segunda.

Pues sí, me pareció especialmente gráfico el acierto de tu precisión inicial sobre la diferencia clave que hay entre «pesar»y «sopesar» [tu primer $\ 1: 39$ y ss.]. Así esta precisión fundamental queda más intuitivamente presentada que mediante el término técnico correspondiente: inter-subjetividad de la medición, para diferenciar lo primero. No obstante, mi impresión es que, a pesar de lo acertado de la generalidad de tus observaciones, al fin de cuentas te dejaste llevar al terreno propio de ATIENZA: esto es, a encarar esas cuestiones principalmente en el plano de lo que he llamado «novelas de conceptos» teoréticos (así RAWLS, HABERMAS, LUHMANN, etc.). En los discursos inspirados por tales o cuales novelaciones doctrinario-jurídicas (p. ej.: ALCHOURrón y Bulygin, Dworkin, Alexy, Ferrajoli, etc.) se dan ciertos entreveros de planos - novelas ejemplares / realidades prosaicas - como unos que, mutatis mutandis, tan bien ilustra el filme de Woody Allen, The Purple Rose of Cairo [me he explicado con amplitud sobre ello en mi estudio publicado en el número anterior de Doxa $]^{4}$.

A mi juicio, también los términos en que se ha desarrollado ese debate se apuntan en buena medida a algo así como una suerte de «The Purple Rose of Judicial Process». A continuación trataré de ir señalando algunos puntos clave donde las relaciones entre ambos escenarios — «novelaciones» doctrinarias/pragmática discursiva judicial— permanecen allí bastante relegadas entre bambalinas, como es habitual en los planteamientos dirigidos a elucidar cuestiones de ese tipo.

4 Cfr. E. P. HABA, «La opción capital para los discursos jurídicos: ¿novelas de conceptos o una tecnología social?», Doxa, núm. 36, 2013, 509-550. 


\section{PREGUNTAS CRUCIALES SOSLAYADAS}

Tú haces ver muy bien distintos puntos flojos (por así decir) que son esenciales en la construcción semántica de esos relatos llamados «ponderación». Has percibido, y hasta señalas varias veces al pasar, la gran indeterminación que caracteriza a los trazos de algunos de sus principales «personajes»-conceptos: así tu aguda observación sobre la diferencia entre «arbitrario» y «discrecional» [114], como también sobre la endeblez de la diferencia pregonada entre «reglas» y «principios» $[78 \mathrm{y} \mathrm{ss.].} \mathrm{No} \mathrm{obstante,}$ pasas simplemente por encima (mas no descarto que te hayas dado cuenta aun sobre esos aspectos) de las invocaciones a fórmulas lingüísticas cuyos contenidos son enormemente gelatinosos y no menos enormemente manipulables. Así, entre otras expresiones (cito a ATIENZA, con cursivas mías):

— «[...] requisitos (= la pretensión) de coherencia, universalidad, bondad de las consecuencias (= producen consecuencias socialmente aceptables, positivas) y respeto de la Constitución», todo eso presentado como rasgos definitorios de lo ahí llamado «racionalidad» [35 y ss. y 108];

— «[...] existe una regla, pero por alguna razón, la misma resulta inadecuada»; es cuestión de ver «si existe o no una regla del sistema que regule aceptablemente el caso» $[28$ y ss.]; «...ese riesgo no se combate oponiéndose in toto (curs. del A.) a la ponderación, sino oponiéndose a que se pondere cuando no debería hacerse (o por quien no debería hacerlo) y a que se haga de una manera inadecuada» [102 y ss.]; [Ahí la pregunta crucial, soslayada no menos por ti que por Manolo, es ni más ni menos que aclarar lo siguiente ( chica cosa!): adecuada o «inadecuada», «aceptablemente» o no, «no debería» o sí, pero... ¿a juicio de quién o quiénes? Y si bien ATIENZA llega a formular una pregunta semejante ( «ंAceptablemente? ¿Desde qué punto de vista? ¿Para quién?», 103), no es que acaso plantee tal dificultad asignándole carácter general para lo de la ponderación «in toto». Y no se ve, por cierto, que él considere esta dificultad no menos válida asimismo en relación con afirmaciones como las otras suyas que acabo de transcribir (i.e., las de sus 28 y ss., y 102 y ss.); con dichas preguntas él se refiere únicamente a un pasaje tuyo particular, ése que recoge entrecomillado inmediatamente antes de ellas (con respecto al cual advierte, por lo demás, que ni siquiera le «ha resultado fácil saber qué es realmente lo que piensas [...]»)].

- es dable «[...] lograr casi siempre una (única) respuesta correcta: una respuesta justa y conforme con el derecho» [95]; «existe siempre, o casi siempre, una única repuesta correcta para cada caso (pero a la vista de todas las circunstancias que lo caracterizan)» [136 y ss.]; «[...] sólo muy excepcionalmente podría configurarse una laguna axiológica... [pues éstas serían apenas unos pocos casos con respecto a los cuales] pensaba [y sigo pensando (dice ATIENZA)] que es imposible dar criterios precisos» [104]; rado

— existencia de propiamente el (¡uno solo!) «sistema» jurídico del país conside-

5 A decir verdad, la expresión «sistema jurídico» aparece muy poco en esa discusión (p. ej.: 28 in fine), mas tengo la impresión de que ella está implícita en las demás fórmulas vacías que arriba señalo entrecomilladas [y vid. infra: $\mathbb{\$} 5$ ]. De todos modos, aunque no se maneje dicha expresión específicamente, basta con las demás para configurar la tónica discursiva general —vaguedades contra vaguedades, «novelas» de conceptos— a que me refiero. 
- sería viable que unos intérpretes del derecho se rijan (¡de veras!) por la «deferencia hacia el legislador» [15], entonces es cuestión de acudir al pensamiento de «el legislador» [97 y ss.] como criterio interpretativo posible (vale decir: señalar a título de una alternativa propiamente «racional» las invocaciones al topos retórico «Voluntad del Legislador», como si acaso el conocimiento de sus contenidos pertinentes decisivos fuera un asunto comprobable empiricamente mediante verificaciones propiamente dichas, para resolver conflictos de interpretación);

- los intérpretes se podrían ajustar (¡de veras!) a seguir «una prioridad en favor de la libertad, o a favor de la constitucionalidad de una ley (deferencia hacia el legislador)» [15] (así se da por presupuesto que el entendimiento de estos dos términos básicos es bastante unívoco, siempre o casi siempre, de modo tal que no cabrían mayores discrepancias en cuanto a quiénes sean los «candidatos» positivos y quiénes los negativos, en la realidad, como referentes pragmáticos de ámbitos de significación determinados por dichos términos respectivamente);

— remitirse a «la satisfacción del interés público» [18] (es otra fórmula vacía de la retórica política en general y de la retórica jurídica también);

- etcétera.

Recapitulo los ítems principales de este catálogo de conceptos altamente indeterminados, esto es, plenos de interpretaciones muy contradictorias entre sí (según los respectivos tipos de gustos «técnico»-doctrinarios, cuando no unos principalmente «ideológicos», de los intérpretes):

— «coherencia, universalidad, bondad» de las consecuencias, socialmente «aceptables, positivas»;

— regla «inadecuada», por «alguna razón», en contraposición a la regla que regule «aceptablemente» el caso;

— aquello que no «debería» hacerse;

- la respuesta «correcta», «justa» para cada caso, a la vista de «todas» las circunstancias que lo caracterizan;

— «la constitucionalidad» de una ley, deferencia hacia «el legislador»;

— en favor de «la libertad»;

— «el interés público».

Es sintomático que ATIENZA dé simplemente por consabida la validez cognoscitiva de tales letreros, sin que él —ni nadie, que yo sepa, entre quienes sostienen esas habituales fantasmagorías doctrinarias - intente responder ante las objeciones específicas presentadas frente a dichos comodines lingüísticos. Tampoco tú cuestionas tal validez, hasta donde he podido darme cuenta, al menos en tus observaciones de la presente discusión. Y aunque a menudo has criticado lo de la «única» respeta «correcta», empero terminas recayendo en algo bastante parecido a eso en cuanto a aquellos casos para los cuales no admites como «posible» unos sentidos que ATIENZA y otros juristas afirman poder reconocer como tales.

No te voy a aburrir con la mención de estudios [KELSEN, Ross y demás] en donde a dichos fantasmas lingüísticos se les ha bajado la careta (por supuesto, no es indispensable conocer además mis propios trabajos al respecto). De cualquier manera, lo cierto es que ni tú ni Manolo toman en cuenta para nada, allí, semejantes objeciones. 
¿Será que éstas no tienen por qué venir a cuento para lo discutido abí, o que en todo caso su importancia sería sólo secundaria para tales efectos? Es bien posible que así sea, siempre y cuando la discusión se conforme con hurgar en determinados planos discursivos donde, sean éstos cuales fueren, las cuestiones se plantean principalmente (por no decir exclusivamente) con vistas a elucidar unas eventuales idas y venidas de ciertos conceptos manejados en-sí-y-por-sí, vale decir, no interrogados más allá de sus propias autocaracterizaciones dogmáticas.

Para todo realista, en cambio, lo verdaderamente interesante comienza a verse cuando se plantean otras preguntas, esto es, traspasando la mera reverencia discursiva ante unas mayestáticas palabras todo ubicuas como «coherencia», «universalidad», «bondad», «libertad», «justicia», «correcto», «adecuado» o «inadecuado», etc. El realista, cuando es cuestión de ocuparse de tales palabras, pues efectivamente ellas pueden también no ser ajenas a unas repercusiones prácticas importantes, empieza por preguntar, antes que nada y por encima de todo: ¿cuáles son los efectos reales considerados? — ijustamente ésos que quedan aparte del ruedo en las gestas académicas noveleriles a propósito de dichos términos cómodamente invocables por tirios y troyanos!- Sí, él se preocupará por saber: ¿«libertad» de quiénes o «adecuación» para hacer qué especies de cosas específicamente?, ¿«universalidad» para imponer como conductas los «intereses» preferidos por quiénes?, ¿«coherencia» según el pensamiento de quiénes?, etc. [acerca del término-bandera «libertad», puede verse los sitios indicados en la n. 12 (infra). Por qué constituyen justamente unas fórmulas vacías ${ }^{6}$ las invocaciones a categorías como «universalidad» y «coherencia», en el modo cómo las presentan las teorizaciones de la corriente «estándar» a propósito de la argumentación jurídica, lo he explicado de paso en mi estudio «Avatares...» $\left.{ }^{7}\right]$.

$* * *$

La cuestión CRUCIAL que, a mi juicio, queda muy diluida en los términos como se plantea vuestro debate, sin perjuicio de todas tus penetrantes observaciones y también las de Manolo, me parece que es básicamente: ¿cuestiones de palabras o cuestiones de hechos? [cfr. VAZ FERREIRA, Lógica viva ${ }^{8}$ : el cap. correspondiente]. En cuanto se presta atención a la importancia de distinguir entre estas dos cuestiones, entonces salta a la palestra inevitablemente el asunto de la NO-IGUALDAD y la carencia de relación UNÍVOCA entre intentio (semántica) y extentio (pragmática) de las conceptuaciones invocadas

6 Para una caracterización general del tipo de pensamientos que constituyen «fórmulas vacías» vid. E. P. HABA, Metodología jurídica irreverente. Elementos de profilaxis para encarar los discursos jurídicos terrenales, Madrid, Dykinson, Sec. C.I.4, 2006 (197 y ss.). La totalidad de los materiales contenidos en ese libro han pasado a formar parte, revisados, de una obra muchísimo más amplia: E. P. HABA, Metodología (realista) del Derecho. Claves para el razonamiento jurídico de visión social práctica, t. I y II (impresos) + t. III (CD), San José (C. R.), Editorial UCR, 2012 (www.libreriaucr.com/catalogo/): ahí la Sec. D.II.3 (453 y ss.). O bien, cfr. E. P. HABA, Axiología jurídica fundamental. Bases de valoración en el discurso jurídico (Materiales para discernir en forma analítico-realista las claves retóricas de esos discursos), Ciudad Universitaria Rodrigo Facio (San José, C. R.), Editorial UCR (www.libreriaucr.com/catalogo/), ed. corr. y ampl. (la ed. or. es de 2004): ahí Sec. G.IV (250 y ss.) y Compl. $\beta$ (357 y ss.), 2008, sitios donde se ofrecen también numerosos ejemplos; una reedición de esta obra será oportunamente publicada, en el mismo sitio, bajo el título principal Las valoraciones de los juristas.

7 E. P. HABA, «Debate sobre Teoría de la Argumentación: Avatares de lo "racional” y lo "razonable", cuando son eximidos de tener carnet de identidad», en RTFD, núm. 14 [ref. supra, n. 3]: $\mathbb{S}$ II.3 (esp. 271 ), 2011. Ese texto forma parte también de la obra señalada en la n. 3 in fine.

8 Ref. supra: n. 7. 
por ATIENZA. Todo ello relacionado también, en muy buena medida, con que esos planteamientos aparecen acuñados en términos de falsa precisión [cfr. ibid.: el cap. correspondiente]. Por tu propia parte, si bien no dejas de indicar algunas indeterminaciones, aun estos señalamientos tuyos vienen a diluirse en buena medida: pierden «protagonismo» en medio del cúmulo de cuestiones-de-palabras adyacentes en las que, siguiendo a Manolo, te detienes mucho tú también.

A su vez, estrechamente vinculado con esa NO-discriminación básica, hay también otras cuantas incógnitas más por aclarar, para poder saber qué alcances se supone (¡aun según ustedes mismos!) corresponda entender que tienen vuestros propios planteamientos:

- ¿CUÁLES serían, entre los juicios de valor manejados por ustedes, los de tipo categórico y cuáles los de carácter instrumental? ${ }^{9}$ [y: i) ¿en qué medida —que resulte bastante comprobable - pueden ser, de hecho, intersubjetivos los criterios con que en las prácticas lingüísticas respectivas son manejadas esas etiquetas? // ii) ¿qué «pruebas» empíricas, aunque sean aproximadas, se consideran en cuanto a cada uno de los juicios instrumentales, si es que los hubiere entre las consideraciones efectuadas por ustedes?].

- ¿QUÉ se presenta ahí como principalmente descriptivo (ya sea de unos hábitos lingüísticos o de unas conductas pragmáticas vinculadas con estas costumbres discursivas) y, en cambio, qué ha de entenderse esencialmente como propuestas para acomodar unas presentaciones semánticas en la actividad judicial (sea o no sea que estas últimas tengan ya algunas intervenciones allí mismo)?

- ¿CUÁLES de los términos básicos involucrados son de manejo pragmáticamente INTER-subjetivo, y cuáles no? (a esto último sí te has referido, básicamente con la iluminadora diferencia señalada entre «pesar»y «sopesar», pero de todos modos dejas pasar como si tal cosa comodines lingǘsticos multirretóricos tan remanidos como los que te señalé antes: «pretensión de universalidad», «coherencia», «adecuación», «el legislador», etc.).

Claro, mis preguntas son muchas (...y podrían ser bastantes más). Tanta «preguntadera» puede producir incomodidad entre cultores de la teoría del derecho, suscitarles acaso la sensación de que para ésta misma no se vale someter sus temas a la elucidación de detalles tan pedestres. Las perplejidades claves que semejante lista de cuestiones pone sobre el tapete son cuestiones acerca de las cuales los escritores de esa disciplina concuerdan (tácitamente) en apartar la vista.

9 Sobre la diferencia, ;fundamentalísima!, entre estos dos grandes tipos básicos de juicios de valor necesitaré llamar la atención, otra vez más, en varios sitios del presente texto. Aunque tal diferencia es elemental, rara vez suele ser traída a colación en las abundantes elucidaciones que con respecto a cuestiones valorativas tienen lugar en estudios de teoría del derecho [unos señalamientos generales básicos sobre la naturaleza y alcances de dichas dos cardinales categorías del pensamiento para la llamada «Razón práctica» se pueden hallar en E. P. HABA, Los juicios de valor. Elementos básicos de Axiología General, San José (C. R.), Editorial UCR (www. libreriaucr.com/catalogo/), Sec. F.II, 2010; y vid. las obras de referencia ahí señaladas (principalmente M. WEBER y A. BRECHT). Hay ediciones anteriores de dicha obra, publicadas por la misma editorial, a partir de 2004: allí la misma sección. El asunto es considerado también, de manera mucho más breve, en Metodología jurídica irreverente [ref. supra, n. 6] Sec. C.III.5; más amplio en Metodología (realista) del Derecho, ref. en la misma n., ahí Sec. E.III (recoge la mayor parte del material contenido en la Sec. F.II de Los juicios...)]. 


\section{PALABRAS Y «HECHOS»(Y EL ASUNTO DE LAS «PRUEBAS»)}

Tal vez haya quienes, no sé si también tú, entiendan apropiado objetarme algo así como las dos puntualizaciones siguientes: a) Las «palabras» (y así podría tal vez ser en cuanto a las etiquetas discursivas acerca de las cuales queda planteada la controversia entre ustedes) no son ajenas a grupos de «hechos»; por lo demás, no siempre está claro qué es o no es un «hecho». b) Muchas veces no son concluyentes las «pruebas» que puedan recabarse en cuanto a la efectiva «instrumentalidad» de lo señalado en cierto juicio de valor (y así podría ser en cuanto a los manejados por ustedes), sin perjuicio de que esa «instrumentalidad» pueda darse en algunos o muchos otros casos de la materia considerada. Ambas precisiones son acertadas, mas no afectan a lo sustancial de mis observaciones. Me explico:

a) Ello es verdad como observación generalísima, o sea, IN-discriminada. Sólo que, hay «hechos» y «hechos»... Pero aquí (i. e., para el asunto «ponderación») no se trata, digo yo, de elucidar esa cuestión epistemológica EN GENERAL, sino de considerar la diferencia entre estas dos categorías básicas — «palabras»/«hechos»— con respecto a las cuestiones especificas puestas sobre el tapete en vuestro debate. O bien, ¿será que tal distinción carece de importancia para ese asunto o acaso resulte imposible de identificar para lo examinado ahí?

No pretendo negar que abundan los «hechos» lingüísticos, ni que muchísimos de éstos tienen influencias decisivas sobre conductas vinculadas con ellos, por mediación de la mente de sus protagonistas. Eso sí, no creo que sea exactamente lo mismo DECIR que HACER. Por el contrario, formulado técnicamente: semántica $\neq$ pragmática lingüística. Si bien caben correspondencias entre ambas esferas, no es obvio dar por descontado de antemano que tales correspondencias existan de veras: ésos son asuntos para ser elucidados empíricamente, caso (o tipos de casos) por caso(s). Claro está, reconozco que también el pronunciar palabras o poseer ideas en la mente son unos «hechos», en sentido amplio, pues tanto lo uno como lo otro tienen lugar realmente; pero no es a tales tipos de «hechos» que entiendo referirme, sino justamente a cuanto $N O$ se agota en un decir o un pensar, ni tampoco consista simplemente en ciertas emociones anejas. Llamo «hechos», en sentido estricto, a: fenómenos que son también (cuando no exclusivamente) extra-lingüísticos (aunque puedan venir codeterminados y cointegrados por desempeños lingüísticos), ya sean ellos puntuales o que se reiteren en regularidades - legaliformes o probabilísticas o al menos estadísticas-como acontecimientos típicos.

Si acaso alguno de ustedes me dijera que tal diferencia no existe, simplemente no veo de QUÉ podría yo venirles a hablar en cuanto a los asuntos planteados. A mí, la semántica jurídica no me interesa en sí y por sí («novelas de conceptos»), sino únicamente en tanto en cuanto ella sea capaz de codeterminar — io no!- la PRAGMÁTICA (¡repercusiones sociales reales!) de los discursos en cuestión. [En cuanto a esto último, ATIENZA ha reconocido paladinamente (Doxa, 33: 408, punto 4) que, según él mismo: «...diferenciar con precisión los elementos descriptivos y prescriptivos de las argumentaciones jurídicas me parece EQUIVOCADO...» (cursivas mías). En cambio, tú has subrayado que compartes la tesis contraria: «...se trata de resituar y justificar la DISTINCIÓN entre teoría descriptiva y teoría normativa de la argumentación jurídica...» (ibid.: 441 
in limine, cursivas mías). No obstante, me parece que también en tu propia argumentación has caído, en largos trechos de esos comentarios, en unas indistinciones como la encomiada por Manolo. En vez de poner ahí acento en tal distinción precisamente, al desmenuzar las novelaciones (categorización mía) de ATIENZA sobre unas «razones» jurídicas, más bien le has seguido el juego, concentrándote sobre todo en ese mismo plano. Criticas, sí, los «personajes» semánticos de él; pero lo haces por lo general sin subrayar que ellos son eso, unas criaturas esencialmente SEMÁNTICAS (y de intentio bien «gelatinosa», por lo demás). Si bien el tener estas creencias iusnoveleras, unas u otras, puede no estar libre de consecuencias efectivas —aquí se trataría del ejercicio efectivo más amplio o más restringido de unos grados de «libertad» por parte de tales o cuales jueces - cuando hay quienes se dejan guiar de veras por tales fantasmagorías, no quita que éstas en sí mismas sean lo que son: ¡unas storytelling!]

b) Por supuesto que no se trata, según veo yo ese asunto, de pedir «pruebas» concluyentes (cuando no fuere dable obtenerlas), sino de indicar, sin disimulaciones «noveleras»: 1) concretamente cuáles serían unas «pruebas» empíricas aproximadas que sea posible ofrecer al respecto, para hacer más o menos plausible la instrumentalidad («servir» para...) afirmada, si es que se pretende sostener que hay tal; 2) o bien, reconocer francamente que no existen semejantes «pruebas», ni siquiera en alguna medida, de modo que creer o no creer en tal instrumentalidad práctica es una cuestión de adivinación o de intuiciones «inefables». [Posiblemente se pueda a veces acertar adivinando o dejándose llevar por ciertas intuiciones, así algunas parasicológicas; pero entonces uno no debiera abstenerse de reconocer que es justamente éste el terreno en que se mueve su discurso sobre las cuestiones en examen. Supongo que no es tal el plano de pensamiento en que entiendes moverte tú; y acaso ni siquiera Manolo, aunque él mismo forme parte de la legión de quienes tendrían la especial facultad de lograr aprehender valores absolutos (cognitivismo axiológico)...].

$$
* * *
$$

En función de todo ello, si bien creo que tú mismo te das cuenta de esas cosas, pienso que el lector desprevenido, sobre todo el acostumbrado a moverse principalmente en el plano de las novelas de conceptos predominantes en la teoría del derecho (y, a decir verdad, difícilmente sean otras personas quienes se interesen en estos debates), verá vuestra discusión como un capítulo más de eso mismo: «personajes» teoréticos van —unas estipulaciones semánticas- y «personajes» teoréticos vienen —otras estipulaciones semánticas—, sin poner en tela de juicio el gran «cielo» que los cobija en común. En fin, yo no alcanzo a distinguir acerca de qué HECHOS (en sentido propio, sean ellos discursivos o «materiales») estarían ustedes en desacuerdo sobre si reconocer su EXISTENCIA como tales: ¿Cuáles serían los X fácticos — iterminologías aparte!con respecto a los cuales Manolo cree que sí existen y tú dices que no existen, o a la inversa? ¿En QUÉ discrepan ustedes, salvo sobre si sea recomendable emplear o no ciertas façons de parler? (así, en cuanto recurrir o no a mapas lingüísticos como ésos que componen los pedantes trámites discursivos llamados «ponderación»).

Después de todo, también tú llegas a darte cuenta en buena medida de que éstas son unas cuestiones-de-palabras. Dices:

...yo no veo inconveniente a que llames ponderar a lo que tradicionalmente llamábamos valorar discrecionalmente [...] estaríamos los dos poniendo los significados posibles del enun- 
ciado normativo como límite [...] Que a una parte de ese razonamiento interpretativo yo lo llame valorativo y tú lo denomines ponderativo sería cuestión MENOR sobre la que quizá NO mereciera la pena gastar tantas páginas (128 y 130, cursivas mías).

No obstante, de inmediato acotas: «Pero dudo muy sinceramente, y bien lo lamento, que nuestros acuerdos sean tantos» (130). Tampoco yo dudo que entre ustedes dos haya más de un des-«acuerdo» sobre tales cuestiones. Sólo que, no puedo soslayar la pregunta: ¿des-acuerdos, sí, pero sobre qué HECHOS?

\section{INDIFERENCIA DE HECHO, PARA EL RAZONAMIENTO JURÍDICO PROFESIONAL, DE LA CONTROVERSIA COGNITIVISMO/NO- COGNITIVISMO AXIOLÓGICOS. DOS «POSTURAS» DOCTRINARIAS QUE, A FIN DE CUENTAS, ESTÁN BASTANTE «CERCA» ENTRE SÍ}

Un desacuerdo básico entre ustedes podría residir en eso de que, mientras Manolo mantiene unas creencias epistemológicas que lo ubican de pleno en el plano de los cognitivistas axiológicos, en cambio tú te ubicas más bien entre los llamados «relativistas» (no-cognitivismo) en ese respecto:

...lo que los escépticos en materia moral y iusfilosófica mantenemos es algo distinto: no que carezca de sentido que yo tenga mis preferencias morales, mi idea de la justicia, mi consideración sobre cuál sea la solución más equitativa [...] sino que esas preferencias mías poseen dos características decisivas: la primera, que no es racionalmente demostrable (en un sentido pleno y fuerte de «demostrar») que mis preferencias sean superiores a las de otros, aun cuando mi convicción subjetiva sobre ellas sea total y radical (131) ${ }^{10}$.

Ahora bien, aun cuando estoy básicamente de acuerdo contigo en cuanto a lo apuntado en estas líneas tuyas, no se me oculta que, de todas maneras, la discrepancia que al respecto hay entre ustedes dos no implica desacuerdos sobre si existen o no determinados hechos (¿cuáles serían éstos mismos?), sino sobre cómo pensar acerca de ellos desde ciertos puntos de vista: cómo juzgarlos. Desde luego, dos personas pueden estar perfectamente concordes en reconocer que ha sucedido tal o cual cosa, pero discrepar en cuanto a si eso está «bien» o está «mal», como también sobre qué hacer al respecto. No pretendo decir, por cierto, que este otro plano de pensamientos no pueda ser importante, o hasta importantísimo, tanto para la esfera del conocimiento teorético al respecto como inclusive en sus repercusiones prácticas. Sólo digo que esos dos planos - reconocimiento de unos hechos/ciertas apreciaciones acerca de ellosno son la misma cosa. Para el presente caso, por cuanto en nuestro asunto nos interesa sobre todo (¿o me equivoco?) cuáles sean las consecuencias prácticas de las formas de pensamiento jurídico consideradas, la cuestión principal es saber: ¿en qué medidas, y cómo, lo puntualizado en dicha discrepancia que en materia epistemológica hay entre ustedes dos tenga efectos en la realidad judicial? ¿Será que, de veras, las maneras como resuelven los jueces depende de qué piensen ellos en cuanto a eso específicamente, o sea, según si estén convencidos respectivamente por las razones que ofrecen los epis-

10 Lo que ahí GARCíA AMADO denomina «escépticos» corresponde a la posición del no-cognitivismo axiológico. Para explicaciones sobre las corrientes epistemológicas llamadas «cognitivismo» y «no-cognitivismo» axiológicos, $c f r$. la obra señalada en la n. 9 (supra): vid. la sección C, esp. sus subsecciones I y II ( 51 y ss.); sobre «relativismo» y «escepticismo» en materia de juicios morales puede verse ahí la subsección V (98 y ss.). 
temólogos cognitivistas o las de los no-cognitivistas en materia de teorías sobre el pensamiento axiológico?

No creo que esa discusión epistemológica desempeñe papel real alguno en las mentes reales de los protagonistas reales que dictan las resoluciones judiciales reales, sea o no sea que recurran a esquemas de razonamiento como los llamados «ponderación». Por lo general también aquéllos son cognitivistas axiológicos (i. e., así como Monsieur Jourdan hablaba en «prosa» aun sin saber que se trata de esta categoría gramatical); de hecho es ésa la manera de pensar que cultivan casi todas las personas, por lo menos ante las cuestiones que no les son más bien indiferentes. Por lo demás, como los discursos judiciales cultivan a pie juntillas La Superstición del Único Significado Verdadero (I. A. RiCHARDS), en su aplicación para el mito de que hay una sola interpretación verdaderamente «correcta» para cada caso jurídico, esto implica necesariamente asumir (al menos subconscientemente) tal preconcepción para las valoraciones judiciales. Lo que hace diferencias, eso sí, es si su cognitivismo les lleve a creer en unas u otras ideologías políticas o religiosas, mas no cuáles sean las creencias abstracto-epistemológicas (aun suponiendo que alcancen a tematizarlas como tales, lo cual ya sería mucho decir) a que se adhieren, implícitamente acaso.

En cambio, si hay unas discrepancias de probado alcance práctico entre ustedes dos, sería bueno poner en claro sobre qué aspectos propiamente empíricos versan tales diferencias. De ahí mi pregunta reiterada: ¿des-acuerdos, sí, pero sobre qué hechos? Esta pregunta es de rigor, se hace ineludible, salvo si lo afirmado consista pura y exclusivamente en unos juicios de valor categóricos, o sea, apriorísticamente manejados ahí como in-discutibles (por definición); todas las demás especies de juicios de valor -i. e., los instrumentales - se basan, al menos parcialmente, en unos enunciados con contenidos empíricos, vale decir, sujetos a pruebas y contrapruebas mediante comprobaciones sobre la existencia o inexistencia de ciertos bechos (en sentido estricto).

Tengo la impresión de que en ese debate vuestro no se trata, después de todo, principalmente de desacuerdos entre ustedes sobre adherirse o no a unos juicios de valor categóricos (o bien, habría que ver cuáles son sus contenidos intersubjetivamente precisos, supuesto que acaso fuera posible determinarlos). Ahora que, si efectivamente vuestras discrepancias no se concentran principalmente en diferir acerca de ciertas valoraciones asumidas como categóricas (¿cuáles?), entonces esa pregunta formulada por mí es de lo más pertinente: saber la existencia respectivamente de qué HECHOS sostiene cada uno de vosotros y niega el otro, si es que hay tales, resulta absolutamente decisivo, quiérase o no, para apreciar CUÁL sea a ciencia cierta la verdadera dimensión y los alcances verdaderos de ese intercambio de ideas entre ustedes.

Por mi parte, no he logrado discernir cuáles serían tales «hechos». Por eso tiendo a pensar que al fin de cuentas no le falta razón a Manolo cuando señala, ya concluyendo vuestro debate, que:

aun siendo distintas, nuestras posturas están, al final del debate, más cerca entre sí de lo que probablemente ambos pensábamos al inicio (138, cursiva mía).

Esa «cercanía» consiste, a mi juicio, ante todo en que tanto él como tú mantienen el debate ubicado principalmente en el plano de las «novelas de conceptos» dogmáticojurídicos, las cuales a su vez cultivan enfoques que son tributarios de visiones esencia- 
listas (un esencialismo «razonabilista» frente a un esencialismo «positivo-juridicista», por llamarles así), como así también conservan intactas las enormes penumbras de vaguedades de ciertos conceptos fundamentales a que respectivamente recurre cada uno de ustedes. Eso sí, no faltan ahí las discrepancias en cuanto a cuáles sean vuestros personajes-conceptos preferidos ni a cómo deban algunos de ellos comportarse en las tramas de iusdogmática consideradas.

\section{DISPUTA ENTRE RECOMENDACIONES; RECURSO A UNAS DISTINCIONES INOCUAS. FÓRMULAS DE FALSA PRECISIÓN. ¿CUÁLES SON LOS SIGNIFICADOS JURÍDICOS «POSIBLES»?}

Examinando vuestro debate, llego a la conclusión de que el «qué» principal de enfrentamientos entre ustedes reside, llámesele como se le llame, en cuanto a RECOMENDAR positiva o negativamente, como orientaciones mentales, ciertos patrones heurísticos —así los calificaría yo (también lo hace ATIENZA: 22) — para servir de guías en el razonamiento judicial. Se trata sobre todo, si no estoy equivocado, de lo siguiente: a) papel más AMPLIO o más restringido que se recomienda en cuanto a guiarse por «razones» que puedan ser un tanto independientes de la «letra» de ciertas disposiciones jurídicas invocadas $(106)$; b) consiguientemente, aconsejar a los jueces tomarse mayores o menores LIBERTADES con respecto a la «letra» invocada, para adoptar sus resoluciones.

Aun entendiendo que tanto $a$ ) como $b$ ) son unas recomendaciones, no simplemente comprobaciones, yo estaría de acuerdo en reconocer que pueden marcar diferencias en la producción de los «hechos» consistentes en la parte resolutiva de órdenes dadas por los tribunales. Digo «hechos», puesto que por cierto tales decisiones pueden no ser indiferentes para la «vida» del derecho, o sea, las consecuencias prácticas para individuos de carne y hueso. En efecto, ello puede conllevar ni más ni menos que consecuencias sociales efectivas —i. e., las extrajudiciales y las extraacadémicas-, ya sea individuales o más generales, cada una de las cuales podrían variar en función de cuáles sean respectivamente las recomendaciones doctrinarias seguidas por los jueces (en caso de que realmente las tomen en cuenta ellos mismos).

De todas maneras, la cuestión práctica clave es: 1) para asuntos jurídicos puntuales discutidos realmente en los tribunales, si allí se invocare dichas postulaciones teoréticas, ¿es intersubjetiva tal distinción entre contenidos compatibles con la «letra» y los que no lo son, y entre «razones» legítimamente invocables ahí y «razones» consideradas — por unos juristas sí y por otros no- como extrajurídicas? (p. ej., en cuanto a re-«conocer» si ahí existe o no existe una «laguna axiológica»); 2) ¿cómo aquilatar, intersubjetivamente, si un juez se toma o no se toma ya sea más o ya sea menos «libertades»? (habrá quienes sostengan, con respecto al mismo asunto, que sí se las ha tomado, «excediéndose», mientras otros dirán que no).

Ahora bien, como resulta que los criterios intersubjetivos de tal índole no existen [para detalles se puede $c f r$. mi libro El espejismo de la interpretación literal ${ }^{11}$ y mi estu-

11 E. P. HABA, El espejismo de la interpretación literal. Encrucijadas del lenguaje jurídico, t. I y II, San José (C. R.), Corte Suprema de Justicia-Escuela Judicial, 2003. 
dio «Retórica de "la" Libertad...»"12], lo cierto es que las distinciones propuestas por ustedes en cuanto a 1) y 2) son inocuas. Por más distinguibles que ellas sean entre sí como formulaciones lingüísticas, sus contenidos reales varían de acuerdo con las preferencias del operador jurídico que las invoque. En definitiva, pues, ello no sirve para distinguir decisivamente entre «hechos» $\mathrm{y}$ «hechos», ni para categorizar en qué rubro — ¿«derecho» o no-«derecho»? - entren unas decisiones jurídicas concretas. Eso es manejable poco menos que a piacere para justificar retóricamente tanto determinadas decisiones jurídicas como unas decisiones jurídicas contrarias: ahí están, para que el juez opte, las «razones» que no aceptas tú y las que sí acepta Manolo, los «límites» del derecho detectados por ti y otros «más flexibles» (96) que detecta él...

$$
* * *
$$

¿Cuál sería la manera TRANSPARENTE de tratar estas cuestiones? Basta con sacar a luz, como en muy buena parte has hecho tú, el carácter sustancialmente indeterminado-voluntarista que tienen —ide hecho! — los contenidos invocables bajo las etiquetas asignadas como nociones básicas («proporcionalidad» y demás) para edificar los pedantes mecanismos de pseudo-«objetividad» en que consisten esos procedimientos. Tales letreros conforman unos espejismos de falsa precisión. No es aconsejable. a mi juicio, embarcarse en prolijas disquisiciones terminológicas sobre los «personajes»-conceptos de unas novelas teoréticas como esa storytelling, la llamada «ponderación» de la manera en que habéis abordado vosotros ese asunto. Antes bien, sería bueno concentrarse en des-velar que éstas son, ante todo y sobre todo, eso mismo: unas stories discursivas manejables principalmente a piacere de los operadores jurídicos.

Digo «a piacere», sin ignorar que ninguno de esos locutores es totalmente libre ni aun en el manejo de ese lenguaje, pues a fin de cuentas quedan vinculados por ciertos «núcleos» de significados básicos de dichas costumbres lingüísticas. Sólo que, en tal sentido cada juez jurídico no está más «atado» discursivamente por presentar su argumentación mediante los «casilleros» conceptuales en que consiste la ponderación tipo ALEXY, que cuando lo hace de cualquier otra manera entre las jurídicamente consabidas en el gremio de los juristas profesionales. No menos en tal primera manera que en las demás, el operador judicial que las invoca se está acogiendo, ¡así!, a igual LIBERTAD de decisión en cuanto a la amplia «penumbra» de los conceptos invocados y de las posibles relaciones entre éstos mismos.

Con o sin presentarlo mediante esos formularios llamados «ponderación», después de todo resulta que el operador jurídico hace siempre lo mismo básicamente, en los casos controversiales: ELIGE él mismo, o resolviéndose a seguir ejemplos de elecciones semejantes ya establecidas por otros jueces, entre unos topoi en el seno de los repertorios jurídicos aprendidos para desempeñarse como jurista. Es cierto que para

12 E. P. HabA, «Retórica de "la" Libertad contra las libertades (Control sobre las libertades, por medio de "la" Libertad como ideología)», Revista de Ciencias Jurídicas (Universidad de Costa Rica), núm. 75 (mayoagosto 1993), 1993, 113-158 [es su versión definitiva, revisada y ampliada; la ponencia original se encuentra en Memoria del X Congreso Mundial Ordinario de Filosofía del Derecho (IVR), vol. VI, 163-183 (www.bibliojuridica.org/libros/1/422/19.pdf)]; una versión ya ampliada se publicó en Revista de Filosofía de la Universidad de Costa Rica, vol. XX, núm. 51, junio 1982, 55-69 (bttp://inif.ucr.ac.cr/recursos/docs/RevistadeFilosofia UCR/Vol. XX/No 51/Control sobre las libertades por medio de la libertad como ideologia.pdf)]. 
motivar sus elecciones suele fundamentarlas; pero aun estas fundamentaciones no son, al fin de cuentas, sino esquemas de enlaces discursivos «tópicos», asimismo aprendidos y no menos opcionales cuando hay desacuerdos sobre las soluciones concretas. Yo no digo que no se pueda, y mucho menos que no se deba, razonar con respecto a los topoi en juego. Mas una cosa es hacerlo con base en disimulos - i. e.: no distinguiendo entre juicios de valor categóricos e instrumentales, acudiendo a encubrir con formulismos lo que no son sino unas opciones propias del intérprete, etc. - y otra sería si fueran puestas lo más FRANCAMENTE posible las cartas jugadas sobre la mesa: responsabilidades personales del operador al optar por una interpretación en vez de otra, grados de probabilidad o de improbabilidad de los conocimientos empíricos invocados, etc. Posiblemente esta segunda posibilidad constituye una utopía, pero eso no quita que la primera consista en aquello otro.

Estoy muy de acuerdo con ATIENZA en cuanto a que: «El mejor teórico del derecho es el que hace fácil lo difícil, no difícil lo fácil» (23). A mi juicio, las «técnicas» de ponderación presentadas por ALEXY son un ejemplo paradigmático de lo segundo, mediante los andamiajes de artificios discursivos en que consisten tales «técnicas» de falsa precisión (bueno, los hay también más extremos: ¡el premio mayor se lo llevan, por mucho, las axiomatizaciones de FERRAJOLI!) ${ }^{13}$. Mas tanto tú como aun Manolo mismo terminan por reconocer que, después de todo, la «madre del cordero» está ni más ni menos que en saber CÓMO determinar cuáles serían las «interpretaciones POSIBLES» (106, 122-124 y 135; cursivas mías). Dices al respecto:

poniendo los significados posibles del enunciado normativo como límite para [...] lo que se puede con propiedad llamar aplicación del derecho (130, cursivas mías).

Se trata, pues, de qué sea RECONOCIDO ahí como «significados posibles». Sólo que en el tintero se les quedó a ustedes la pregunta clave para la práctica: ¿por parte de QUIÉNES necesita ser ello reconocido de tal manera?; ¿y por parte de quiénes, en cambio, poco importa que éstos mismos no reconozcan que es así?

13 Hasta donde estoy enterado, el único estudio crítico publicado que va verdaderamente a fondo en cuanto a des-velar la rotunda endeblez de que adolecen los planteamientos centrales de ese afamado autor es el singular (por lo inusitadamente des-velador al respecto) examen de M. E. SALAS, «Sin derecho ni razón. Sobre el garantismo penal de L. Ferrajoli: su carencia de validez científica y de practicidad real», Doxa, núm. 35, 2012, 751-789 [en el mismo ejemplar de Doxa, muy pocas páginas después (819-832), también hay otro comentario crítico con respecto a unas ideas de dicho autor; en este otro no se toca ninguno de los puntos-eje puestos de relieve por SALAS (mas no tenía por qué conocerlos ese comentarista). En la entrega siguiente de esta Revista (núm. 36-2013) nos encontramos con unas cuantas páginas de contestación (559-570) por parte del propio FERRAJOLI, frente al segundo comentario. En cambio, ni él mismo como tampoco ninguno de los tantos admiradores suyos cuyos comentarios fueron especialmente escritos en su homenaje para los núms. 31-2008 (201-334) y 34-2011 (jin toto!) de esta misma Revista, han considerado del caso efectuar referencia alguna a las observaciones de SALAS, y menos que menos tratar de indicar en qué pudieran estar acaso equivocadas del todo o en parte. Aventuro un pronóstico: ;no lo han hecho ni lo harán! Et pour cause...]. Inclusive yo mismo no he dejado de tratar de hacer advertir, aunque apenas de paso, por qué planteamientos como los de FERRAJOLI pertenecen esencialmente al género «novelas de conceptos»: c fr. sobre todo en mis estudios «Callar o no callar [...] that is the question! Entre "crítica crítica" y las críticas-poco-críticas» (Doxa33: esp. 383, n. 38) [recogido también en el libro que he señalado en la n. 3 in fine] y «Sobre la opción capital» [ref. supra: n. 4]; de este último vid. esp. «Novelística de Ferrajoli...», digresión ubicada allí inmediatamente después de la n. 30). 


\section{6. ¿CÓMO CONOCER LOS «LÍMITES» DEL «DERECHO» POSITIVO? [I]: DOS MANERAS ENFRENTADAS, PERO IDEALISTAS AMBAS (STORYTELLING), DE CONCEBIRLOS; Y LA METÁFORA DE ENTENDER EL DERECHO COMO UNA «EMPRESA» (RELATIVO ACIERTO, PERO TAMBIÉN PROCLIVIDAD AL MISTICISMO, MEDIANTE ESA IMAGEN)}

Vuelvo sobre los dos puntos claves a) y b) hacia los que he querido dirigir tu atención más atrás $[\mathbb{\$} 3]$. Si al respecto fuera cuestión de responder realísticamente, vale decir, ya no desde tal o cual «cielo» doctrinario, sino antes que nada advertir cómo pasa y cómo pueda pasar eso en las «tierras» jurídicas — tribunales, administración, etc.-, entonces lo de saber en dónde hallar respuesta a esas dos cuestiones resulta (para cualquier lingüista realista) bastante obvio, elemental. Esto es: el tener presente que la palabra «derecho», como cualquier otra, significa ni más ni menos que lo que realmente ella significa en las mentes de grupos de locutores habituales de ese término; ya sea para todos esos grupos o para cada uno de éstos diferencialmente, en los tipos de situaciones consideradas. Sólo las prácticas lingüísticas MISMAS pueden dar a conocer cuáles sean esos grupos de significados típicos. Lo propio pasa, por ende, en cuanto a los limites establecidos para dicha palabra. Resultan estar marcados de hecho, aunque por lo general no se hallan codificados expresamente: son las elasticidades que en su empleo sean toleradas por tales o cuales sectores de sus locutores, en sus prácticas discursivas jurídicas mismas. KANTOROWICZ, LLEWELLYN, FRANK y otros supieron advertir eso desde hace tanto tiempo atrás, aunque no lo formularon en el marco de los conocimientos de lingüística que hoy están muy al alcance de la mano.

Eso mismo es aplicable, desde luego, no sólo para la pregunta generalísima de qué sea «derecho» in genere, sino igualmente para conocer cuáles son las interpretaciones jurídicas realmente posibles de determinado precepto del derecho positivo en relación con algún caso presentado ante un tribunal de justicia. Señala al respecto:

cuando hablamos de interpretaciones posibles nos referimos a los distintos significados que podemos dar a un enunciado legal en lo que este tenga de equívoco o indeterminado, pero no sería «interpretación» posible la que lo haga decir algo diferente de lo que «de manera inequívoca» dice. [...] Yo pongo como límite del respeto a la norma el respeto a sus interpretaciones posibles, por lo que cuando no hay más que una interpretación posible no tiene el juez margen de maniobra (con arreglo a derecho) [124 y ss., cursivas añadidas].

Ahora bien, todo el asunto es: ¿QUIÉNES serían, según tú, ésos que ahí «podemos», y quiénes los que no «podemos»? ¿Será que «puede» cualquier persona (que conozca normalmente, digamos, el idioma castellano)? ¿O ha de tratarse únicamente de, por ejemplo, los juristas profesionales (y acaso todos ellos o nada más los especialistas de la rama considerada) o en particular los jueces? ¿Y qué pensar si, entre ésos que supuestamente «pueden», sucede que unos juzgan «inequívoco» tal o cual significado como interpretación de un precepto (o conjunto de preceptos o principios) pertinente(s), mientras otros están no menos convencidos de que la interpretación «inequívoca» difiere de aquélla, o acaso hasta hubiere quienes entienden que ninguna de ambas interpretaciones es propiamente «inequívoca» para el caso en discusión? 
En relación con esta última eventualidad, tú llegas a considerar un caso extremo, el de que se presente apenas una sola opinión discrepante; lo cual bien podría hacerse extensivo, consentiría en agregar yo, a la hipótesis de haber apenas un número ínfimo de tales, frente a la abrumadora mayoría de quienes sí están plenamente convencidos de que en la o las disposiciones invocadas está «de manera inequívoca» que ahí «dice» eso mismo que entiende dicha mayoría. Me parece que lo que quieres hacer advertir al respecto es que semejantes casos, por ser tan altamente excepcionales, no vale la pena tomarlos en cuenta para sacar unas conclusiones generales principales sobre el asunto en discusión, como las que ahí se proponen elucidar ustedes dos. Por esto le respondes a Manolo señalando que no sería sensato sostener lo siguiente:

Resulta que yo no puedo mantener la convicción de que una norma $N$ tiene una única interpretación posible si hay en la «comunidad jurídica» una sola sentencia o un solo profesor o tratadista que haya sostenido que las interpretaciones posibles son varias y no sólo la que yo digo (121, cursivas añadidas).

Considero acertada esta precisión. En efecto, los interrogantes planteados por mí no son para referirme a situaciones tan excepcionales. Tampoco van dirigidos a obtener como respuestas unas cifras exactas, digamos la indicación de un porcentaje numérico bien preciso, para establecer lo que sería dable tomar a título de algo así como una «barrera» absolutamente neta entre interpretación «inequívoca» (una sola) e interpretaciones no-«inequívocas» (i.e., admitir que haya dos o más «posibles»). Pues bien, ¿entonces será cuestión de reconocer, como al parecer crees hacerlo tú, alguna interpretación que sea la única «posible» con respecto a tal o cual situación jurídica discutida en los tribunales, aun si de becho hay juristas tan expertos como Manolo y tú mismo que discrepan sobre si de veras sea esa la «única» al respecto? Lo cierto es que para sostener tal cosa acerca de unos casos concretos, así los examinados por ustedes, en modo alguno alcanza con precisiones como las de esos dos pasajes tuyos que acabo de transcribir (tampoco logré detectar otras menos indeterminadas, en tales respectos, a lo largo de tus intervenciones allí).

Lo menos que entonces se debiera determinar muy bien, así fuere estipulativamente, sería unas respuestas que de veras permitan distinguir bastante intersubjetivamente cuáles son los grupos humanos de juristas —iquiénes «podemos»! — capaces de saber a ciencia cierta si determinada interpretación jurídica es «de manera inequívoca» la única interpretación «posible» para resolver un caso dado. Por ejemplo, para ponerlo de manera bien concreta: ¿tal «podemos» comprende también a Manolo, entre otros, o únicamente a quienes estén de acuerdo contigo mismo sobre qué sea «inequívoco» como interpretación jurídica «posible» con respecto a los casos elucidados en vuestra discusión?

Por su parte, ATIENZA señala expresamente que su perspectiva sobre dónde corresponde ubicar los «límites» no coincide con la afirmada por ti:

la función del juez no es hacer justicia a cualquier precio, sino dentro de los límites que le permite el derecho: un juez no debe ser justo, sino justiciero. El otro lado de la medalla es que la vinculación del juez no es sólo a la letra de la ley, sino a sus RAZONES subyacentes (106, cursivas añadidas aquí).

Quiere decir que, si bien ustedes están de acuerdo en sostener que sí hay unos «límites» pre-establecidos (al menos en un espacio-tiempo determinado, supongo), 
empero este acuerdo se esfuma en cuanto se requiere que ello pase a ser planteado en términos lo menos vagos posible. Por vuestra parte, se trata de reducir la indeterminación de los «límites» recurriendo, respectivamente, tú a las «interpretaciones posibles» y ATIENZA a las «razones subyacentes». Mas ni lo uno ni lo otro sirve, de hecho, para identificar unas pautas propiamente dichas. Ambos os contentáis con señalar apenas algo así como dos «horizontes», respectivamente, cada uno de los cuales remite a su propio universo de contenidos bastante in-determinado como conjunto. Tanto es así, la gran in-determinación propia de cada uno de estos dos «horizontes», que pueden llegar a contradecirse hasta las respectivas concreciones a que sus intérpretes arriban para determinar tales o cuales de esos contenidos... ¡inclusive en cuanto al interior mismo del universo discursivo imputado a la etiqueta lingüística invocada así!, llámese ésta lo «posible» interpretativamente o unas «razones» pertinentes.

Interpretaciones «posibles» frente a interpretaciones «posibles», como así también interpretaciones que unos consideran «posibles» frente a interpretaciones no«posibles» que otros consideran «posibles». «Razones» señaladas por unos frente a «razones» señaladas por otros, como así también «razones» que unos consideran pertinentes frente a «razones» que estos últimos consideran no-pertinentes pero otros consideran sí-pertinentes. Y, por supuesto, cada intérprete está muy sinceramente convencido de que sólo quienes están de su propio lado del «frente a » en cuestión cuentan entre los juristas capaces de re-conocer los «límites» verdaderos del derecho positivo aplicable. Quiere decir que los intérpretes ubicados en el lado de enfrente padecerían de una peculiar ceguera mental que les impide percibir esos «límites» a pesar de ser estos últimos tan incuestionables, la cual puede llevarles hasta a imaginarse que los «límites» serían otros...

$$
* * *
$$

Por cuanto hace a la presente controversia sobre tales límites, estoy convencido de que ni tú ni Manolo tenéis nada de «ciegos». Simplemente es que ahí cada quien opta por preferir que los «límites» en cuestión sean vistos de una manera o de la otra, según vuestros respectivos gustos doctrinarios. Y no seré yo, por cierto, quien ponga en duda que ustedes están en todo su mejor derecho de postular esas preferencias, como teóricos proponentes de éstas o aquellas vías para el pensamiento jurídico. Así como optan los jueces, entre topoi jurídicos que de hecho son creíbles en su medio, así también se opta en el seno de la (meta)teoría del derecho al presentar unos u otros consejos prácticos dirigidos a los juristas profesionales, esto es: al proponer aquellas recomendaciones de discursividad que cada teórico suele llamar «racionales» o «razonables» para esos efectos, o cuando uno asegura que los «límites» son indudablemente tales y el otro está plenamente convencido de que son cuáles. Ambos teóricos (ahí son Manolo y tú) se expresan así de acuerdo con pautas que forman parte de tales o cuales juegos lingüísticos que suelen imputarse — itodos ellos! - a la palabra «derecho», por más que las unas puedan resultar antinómicas con respecto a las otras. Tanto los «límites» identificados por ti como únicos «posibles» en discursos jurídicos, como también aquellos otros «límites» identificados por ATIENZA como no menos «posibles» para dichos discursos, corresponden a costumbres lingüísticas cultivadas respectivamente por grupos de juristas a quienes sin disputa se reconoce como conocedores de esta profesión. 
[Estoy dando por sentado aquí que la utilización del término «posible» entiende referirse a un tipo de hechos: ahí son unos hábitos lingüísticos cultivados realmente, por grupos no ínfimos de locutores, para una actividad determinada; aunque fuere a veces sí y a veces no, o por unos locutores sí y por otros no. Mas si de lo que se trata, en cambio, es de recomendar algunos de esos usos, o de criticar otros, no me parece que una formulación transparente, para hacer ver que estamos en ese plano justamente, sea llamarle «límites posibles» a ello; antes bien, entonces corresponde identificar estas pautas como: «límites deseables» o «límites convenientes» o «límites mejores», etc. Esto es dable dejarlo aclarado tanto si se cree (así Manolo) o no se cree (así tú) en un cognitivismo axiológico ${ }^{14}$; sólo es no disimular que se trata principalmente de eso, unos juicios de valor; y preferentemente aclarando también si dichos juicios de valor se entienden como categóricos o como instrumentales ${ }^{15}$. Por tu parte, si bien has sabido marcar muy netamente tus distancias frente a ATIENZA en cuanto a lo del cognitivismo axiológico y a sus consecuencias dogmatizantes para la reflexión sobre el derecho ${ }^{16}$, empero terminas sosteniendo ahora otra especie de cognitivismo normativista, ciertamente no menos supra-empírico que el primero: al parecer, crees en un esencialismo «naturalista» en cuanto a la naturaleza del lenguaje jurídico: infra, $\$ \$ 8$ y 9.]

\section{EL DERECHO COMO «EMPRESA». LAS INTERPRETACIONES DE LOS JURISTAS CONSTITUYEN «APUESTAS» POR HACER ACEPTAR UNOS SENTIDOS COMO NECESARIAMENTE JURÍDICOS}

Es curioso, pero resulta que en cuanto a eso de los sentidos jurídicamente «posibles» estoy bastante menos cerca de suscribir dichos planteamientos tuyos que de admitir que tienen su razón unas metáforas - ipero guardando, claro está, plena conciencia de que son tales! - como las que menciona ATIENZA al respecto. Señala él:

Tú (i. e., GARCÍA AMADO) [...] tiendes a considerar el derecho como un tipo de realidad semejante a lo que es un libro (en cuanto conjunto de enunciados y de significados). Yo propendo a ver el derecho no (o no sólo) como una realidad ya dada, sino más bien como una empresa; como la escritura de una novela (para emplear el famoso símil de DwORKIN), o como la construcción de una catedral (como alguna vez sugirió NINO) o como una empresa de navegación (un símil de JHERING) o como la actividad consistente en contribuir al desarrollo y mejora de una ciudad (que alguna vez he utilizado). Creo que con ello se entiende sin más que no considere que el derecho sea algo «que está ahí afuera y cualquiera puede ver» ${ }^{17}$ (137, cursivas añadidas).

Eso sí, es fundamental no perder de vista, en todo instante, que tales metáforas («empresa», «catedral», «ciudad», «novela») han de tomarse apenas como lo que son, una lejana analogía llamada ahí a título de ilustración literaria. Importa precaverse, antes que nada, de dejarse seducir por cualesquiera de ellas al punto tal de tomárselas demasiado «en serio»: pensarlas ya no simplemente como metáfora, sino asumirlas en

14 Cfr. Los juicios de valor [ref. n. 9]: Sec. C.I.

15 Cfr. los sitios indicados en la n. 9.

16 Por cierto, estoy de acuerdo con lo que has señalado en tal sentido [supra, a la altura de la n. 10].

17 Luego [a la altura de la n. 23] recogeré más íntegramente el pasaje de GARCÍA AMADO donde se encuentran estas últimas palabras, las entrecomilladas por ATIENZA. 
plena credulidad de storytelling disimuladora de cómo funcionan los discursos jurídicos reales (p. ej., de la manera como lo de la «novela» aparece postulado por parte del abogado usamericano al que ustedes no vacilan en plegarse a rendirle vicentianamente tributo de «seriedad» teorética) ${ }^{18}$.

Lo del derecho visto como una gran «empresa» tiene algún sentido realista si se acude a esa imagen para poner el acento en hacer ver que el pensamiento jurídico no es una «cosa» pre-determinada y simplemente externa («ahí afuera«), sino algo que se va haciendo en la «vida» misma de los discursos de derecho. En las maneras como ese orden de pensamientos es desempeñado verdaderamente, por sus actores profesionales reales, se trata ni más ni menos que de: «...una mezcolanza indisoluble de elementos teóricos y prácticos, cognoscitivos y creativos, reproductivos y productivos, científicos y supracientíficos, objetivos y subjetivos...» (según la caracterización insuperable de RADBRUCH que no me canso de repetir, ésta que todas las teorizaciones racionalistas acerca de los discursos jurídicos pasan olímpicamente por alto). En cambio, dicha metáfora deja de tener sentido realista en cuanto lo de la «empresa» es entendido, en todo caso implícitamente, como si en cuanto a la construcción de los discursos jurídicos pudiera eso significar que la preside algo así como alguna, o unas pocas bien determinadas, finalidad(es) general(es) con carácter relativamente unitario, de conjunto (llámesele «sistema» o como fuere). Esto último significa imaginarse que el pensamiento del derecho se da en alguna manera análoga a como se ordenan las actividades de los negocios llamados «empresas» (propiamente dichas), esto es: las presididas por un dueño o una junta directiva, quienes persiguen ciertos bien determinados fines propios concretos (p. ej.: producir mucha cantidad de ciertos objetos y hacerlos accesibles al comercio, o alcanzar el mayor «rating» en programas televisivos, obtener la más alta cifra de ganancias posible, etc.), para lograr lo cual se van produciendo cambios estratégicos en el manejo de esos negocios.

Por cierto, el derecho de cada país va cambiando, mas no lo hace ateniéndose a ninguna planificación de conjunto (salvo que se crea en algo así como el Espíritu hegeliano, o acaso su versión luhmanniana, o alguna otra imaginería de holismo social, lo cual se encargaría de asegurar semejante orden que es en-sí-y-por sí, piensen sea lo que fuere los propios actores humanos de los discursos jurídicos reales). Quiérase o no, las interpretaciones de los juristas consisten en esa gran «mezcolanza» advertida por RADBRUCH. Es verdad que ahí interviene, de todos modos, un amplio núcleo de ideas normativas que se presentan como constantes, en las cuales esa «mezcolanza» se consolida temporariamente para determinado medio social. Hay allí unas costumbres mentales de los juristas — técnicamente dicho: ciertos conjuntos de topoi jurídicos y unas relaciones

${ }_{18}$ Cfr. Doxa, núm. 24 (2001), 165-209 (versión abreviada). La versión completa de ese estudio se publicó en la revista colombiana (Pontificia Universidad Javeriana) Criterio Jurídico, núm. 9 (2009-1), 155-258: «El bluff Dworkin. Su rehabilitación del no-saber en la actual Teoría del Derecho (retorno al realismo ingenuo y apogeo del efecto Vicente, lanzados por una reencarnación más del Prof. Beale)» (bttp://revistas.javerianacali.edu.co/index.php/criteriojuridico/article/view/326/1170). Por cuanto concierne en especial a la modalidad-storytelling en que ese autor presenta al pensamiento jurídico a modo de «novela», vid. el $\$ 5$ en cualquiera de esos dos sitios. Aclaración: si bien de examinar la categoría ius-«novelas» como modalidad doctrinaria general dominante en la teoría del derecho se ocupa también mi estudio señalado en la n. 4 (supra), por mi parte lo hago ubicándome justamente en las antípodas de las disimulaciones-embellecimientos concebidas al respecto por dicho autor $[c f r$. la «Aclaración» ubicada al final del $\$ 2$ en ese estudio mío]. 
normativas estables entre buena parte de estos (todo ello proveniente de leyes, doctrinas, jurisprudencia, etc.) — que normalmente esos locutores profesionales aceptan, en ese medio. Pero tal o cual porción normativa de la «mezcolanza» consolidada puede llegar a variar en cualquier momento: nuevos preceptos oficiales, nuevas aplicaciones doctrinarias, etc. Sólo que, ¡no se puede saber de antemano cuál será la porción que cambie, ni tampoco en qué vaya a quedar modificada entonces! No es dable detectarlo sino a posteriori, cuando la modificación esté ahí; ya sea porque hay unos cambios expresamente introducidos sobre ello en las propias disposiciones oficiales (textos de leyes, decretos), o bien porque se venga a llamar la atención sobre situaciones ante las cuales ahora se ponga en duda cómo entender unas disposiciones aplicables que hasta entonces no habían sido objeto de conflictos de interpretación a ese respecto.

Cualquier interpretación jurídica —ya sea de un solo precepto o de cierta combinación entre varios - constituye, como toda comunicación lingüística, algo así como una «apuesta», por parte de quien la presenta, a que los interlocutores (digamos los jueces de un tribunal) entiendan de la misma manera que el proponente las formulaciones en juego. Tales «apuestas» resultan exitosas por lo general, pues en el círculo de locutores correspondiente es normal que sus miembros manejen muy igual o muy parecidamente un gran conjunto de «códigos» mentales semánticos, ciertos hábitos lingüísticos, de modo tal que lo expresado por un miembro (ajustándose espontáneamente a algunos de esos códigos) es comprendido de manera bastante similar por quienes lo escuchan (ajustándose espontáneamente a esos mismos códigos). Cuando esto no ocurre así, sea por los factores mentales que fuere, la «apuesta» correspondiente falla, en grados mayores o menores.

Ni más ni menos que esto último, unas «apuestas» fallidas, son también los conflictos de interpretación entre juristas. Entonces algunos códigos que en la mente de unos juristas funcionan para ciertas maneras en que su pensamiento procesa tales o cuales porciones del universo lingüístico llamado «derecho», en cambio no funcionan de la misma manera en la mente de otros juristas, pues estos últimos manejan ciertos códigos que son un tanto diferentes para aplicar a la situación jurídica considerada; todo ello sin perjuicio de que para muchas otras situaciones jurídicas sí coincidan los códigos manejados por ambos grupos, lo cual inclusive puede ocurrir acudiendo a alguno(s) de aquellos códigos sobre cuya eventual aplicación no se está de acuerdo con respecto a aquella primera situación.

En eso mismo consisten los desacuerdos entre ustedes dos sobre qué topoi jurídicos corresponde aplicar para resolver los casos judiciales examinados en vuestro debate, como asimismo el señalamiento de las pautas interpretativas de orden doctrinario general que vinculáis con dichos casos tomados allí a título de ejemplo en tal sentido. Contemplado realísticamente, se trata de un no-encuentro entre ciertos «códigos» lingüísticos a que se atiene tu mente y algunos otros a que se atiene la mente de Manolo, siendo imputados respectivamente por cada uno de ustedes (como también por otros locutores jurídicos que comparten unos u otros de esos códigos mentales) al proteico término general «derecho». Tales suertes de des-encuentros entre códigos lingüísticos imputados a dicho término, vale decir, las «apuestas» de comunicación fallidas que se desempeñan en los juzgados y en la academia del derecho, son pan de todos los días en las controversias entre juristas. 
Cada parte, desde luego, entiende disponer en su mente de los códigos lingüísticos «verdaderos» para arribar a la o las interpretaciones «verdaderas», las jurídicamente «correctas», de los textos jurídicos invocados. O de todas maneras, si por acaso se admite (aunque no es nada usual) que podría haber más de una interpretación «correcta» para algunas situaciones, aun entonces cierto código tenido por «verdadero» sin más - i. e., aquel en que cree quien lo asume como tal— permitiría al menos descartar como evidentemente no-verdadera (o jurídicamente no-correcta) tal o cual interpretación sostenida ahí por otros juristas (i.e., cualquiera de ellas que se aparte de las dos o tres admitidas entonces como «posibles» por uno mismo). Así, en cuanto concierne específicamente a vuestro debate, se trata sobre todo de suscribir (Manolo) o de impugnar (tú) ciertos códigos interpretativos invocados como propios para componer lo identificado mediante la etiqueta «ponderación»: tú no admites como «posibles» sino ciertas pautas semánticas, al menos para esos casos considerados por ustedes, mientras Manolo señala como más adecuadas ciertas otras.

\section{8. ¿CÓMO CONOCER LOS «LÍMITES» DEL «DERECHO» POSITIVO? [II]: NATURALISMO LINGÜÍSTICO Y, CON BASE EN ÉSTE, LA PRESUPOSICIÓN DE QUE EXISTE UN «SISTEMA» JURIDICO (...CONFIANDO EN PODER LOCALIZAR ESTA OTRA CUADRATURA- DEL-CÍRCULO)}

Si en vuestra discusión se tratara sólo de hacer ver que respectivamente os gustan más ya sea los procedimientos discursivos llamados «ponderación» o algunos que no se ubican bajo esa etiqueta, y con respecto a los unos o a los otros os preocupara simplemente identificarlos diferencialmente de alguna manera, no tendría yo en principio mayor cosa que objetar. Y me hubiera dado especialmente por contento (en cuanto a mi propios intereses de conocimiento) si por acaso, además, vuestra respectiva opción personal entre estos procedimientos hubiera venido fundamentada, en la medida de lo posible, mediante observaciones empíricas de racionalidad instrumental, esto es: determinar también para qué fines concretos «sirve» mejor acaso lo uno o lo otro, ¡de hecho!, por la presencia ahí de tales o cuales factores conductuales reales comprobados (o comprobables) de las prácticas judiciales correspondientes.

Mas vuestra presentación del asunto, aunque muy cuidadosa en cuanto a deslindar minuciosamente unos topoi de principios jurídico-argumentativos que en efecto son empleados en las instancias judiciales, empero aparece basada en, y dirigida hacia, el esfuerzo intelectual por hallar claves capaces de justificar la creencia en una inveterada cuadratura del círculo: la postulación de que puede haber unos criterios propiamente objetivos, ya sean unos u otros, para dirimir los conflictos de interpretación entre los juristas. [Digo «objetivos» en el sentido siguiente: no porque unos u otros intérpretes consideren apropiado llamarle así a sus opiniones (¿habrá quien no lo haga para las pautas que él mismo acepta?), sino solamente en tanto en cuanto los criterios enunciados sean susceptibles de acreditación inter-subjetiva en el círculo de locutores de referencia, señaladamente para dirimir importantes contradicciones en cuanto a las soluciones específicas que se proponen en casos concretos. Vale decir, que ahí no venga 
a tratarse al fin de cuentas de ingeniárselas en menear unas fórmulas vacías, ciertos comodines retóricos que en la práctica imputan tanto tirios como troyanos a sus respectivas soluciones propias (p. ej.: ¿habrá algún jurista que no considere como debidamente «racionales» o «razonables» las sostenidas por él mismo, junto con colegas que piensen de la misma manera?)].

Sí, se ve que ambos confiáis en estar al tanto de cómo localizar alguna cuadratura del círculo para diferenciar a ciencia cierta entre qué está y qué no está dentro de los «límites» del derecho, aun allí donde los propios juristas profesionales no consiguen ponerse de acuerdo sobre ese «qué» para tales o cuales casos concretos. Ustedes dos discrepan, eso sí, en cuanto a cuál sería esa localización y con qué sea dable encontrarse allí: se refieren, respectivamente, a regiones distintas de esos mundos geométricos donde anidan las certezas lingüísticas supraconvencionales. Manolo está muy convencido de poder conocer los círculos cuadrados en donde residen los valores últimos evidentemente «racionales»; de modo que, recurriendo a tales o cuales entre ellos, según los casos, sería dable proceder a una objetiva «ponderación» que proporcionará la respuesta «correcta» para solucionar las contradicciones entre principios jurídicos. De tu lado, aun cuando desde tiempo atrás has dejado en cueros la presunta «objetividad» de dicho procedimiento en particular ${ }^{19}$, no obstante confías en que existe un cuadrado circular donde estarían localizados los «límites» objetivos pre-establecidos como sentidos «posibles» del derecho aplicable. Por más que al respecto se producen no pocos desacuerdos entre los juristas profesionales, tú entiendes que, al menos en algunos casos (como ésos examinados por ustedes dos), bien puede acontecer que las soluciones jurídicas sostenidas ahí por un grupo de juristas están evidentemente «afuera» (p. ej., ciertas pautas que invoca Manolo) de tales límites, pues «adentro» no podrían quedar sino ciertas soluciones como las sostenidas por otro grupo de juristas (p. ej., las que tú opones a lo sostenido por él).

La raíz y el alcance de estas discrepancias, como tantas otras entre juristas, a mi juicio radican en claves que operan de otras maneras, por cierto muy pero muy distintas a lo que piensa cada uno de ustedes dos sobre ello. A diferencia de lo que pareces pensar tú (si no te he entendido mal), no veo que nadie haya podido detectar —ni en la teoría ni en la práctica- alguna suerte de criterio canónico, ni explícito ni implícito, capaz de permitir reconocer de antemano qué esté DENTRO de los «límites» de lo llamado «derecho» y qué no, allí donde hay disputas efectivas al respecto entre operadores prácticos de esta profesión. Dicho sea de paso, ése es también el error cardinal de LUHMANN (uno de tus autores favoritos, si no me equivoco), quien despista acerca de ello mediante una terminología que es todavía muchísimo más abstrusa y engañosa. En efecto, las teorizaciones de ese autor, como las de muchos otros, dan apriorísticamente por pre-supuesto que, simplemente atenido al hecho de que en el lenguaje se usan unos sustantivos que son diferenciables entre sí como tales: «derecho», «moral», «política», «economía», «cultura», etc., necesariamente $\left[i_{i} ! ! !\right]$ esto conllevaría que de ESO (términos diferentes) se colegiría que también las respectivas esferas de referentes prácticos conforman ni más ni menos que $U N$ «sistema» propio bien determinado cada una, quedando así perfectamente delimitadas entre sí.

19 Cfr. J. A. García Amado, El derecho y sus circunstancias, Bogotá, Universidad Externado de Colombia, esp. $\$ \$ 6$ a $8,2010$. 
Al darse cita ideas muy variadas, aun entre los propios juristas profesionales, sobre QUÉ «entra» y qué no «entra» bajo el multicolor término «derecho» o «jurídico», al menos tratándose de no pocas entre las aplicaciones prácticas al respecto sobre las cuales ellos discrepan, resulta que nadie puede saber a ciencia cierta — salvo para tipos de situaciones muy comunes cuya legitimidad «jurídica» o bien su anti-«juridicidad» nadie cuestiona como tales- QUÉ límites concretos haya entre lo que unos gusten llamar «sistema» jurídico y ésos mismos gusten llamar su «entorno» (de acuerdo con esta despistante terminología de LUHMANN). Según unos juristas, la respuesta jurídica $\mathrm{X}$ está «dentro» del «derecho» (un llamado «sistema», corolario de la ingenuidad lingüístico-naturalística en cuanto a esa palabra); para otros, está «afuera». En la realidad, digan lo que digan unos compuestos discursivos como los de jerga luhmanniana acerca de estos asuntos (tales o cuales stories al respecto puestas en claves de systemtelling), $\mathrm{u}$ otras variedades de iusnovelaciones teoréticas, lo cierto es que existen tantos «derecho» de contenidos DIFERENTES y hasta opuestos entre sí (para el mismo país), y tantos «entornos» respectivos no menos diferentes entre sí, cuantas sean las interpretaciones discrepantes que surjan en cuanto al primero. En definitiva: «derecho» o «sistema jurídico» es un bomónimo, muy elástico, para una infinidad de costumbres lingüísticas que no tienen ningún «límite» general, sino unos «límites» tan variables como lo sean las maneras de «ver» producidas realmente por sus grupos de intérpretes al respecto ${ }^{20}$. No constituye eso ningún «sistema» (salvo recurriendo a esta palabra de modo latísimo: cualesquiera suertes de relaciones).

Semejantes credulidades son ni más ni menos que productos mentales del común naturalismo lingüístico ${ }^{21}$, con su habitual pendant: «La Superstición del Único Significado Verdadero» (RICHARDS). En el plano de las comunicaciones reales, cada uno de dichos términos es imputado a un variopinto conglomerado respectivo de especies de discursos y de conductas relacionadas con éstos. Son especies entre las cuales, en el seno de cada uno de dichos conglomerados, el aludido por la respectiva etiqueta, entre ellas guardan unas escalas de «parecidos de familia» (WITTGENSTEIN), siendo las relaciones entre unas y otras bastante laxas y variables. La unicidad de la denominación tiende a esconder muchas de las más decisivas heterogeneidades internas entre sus referentes, y tanto más cuando la disimulación de ellas es remachada por el espejismo

${ }^{20}$ Mi crítica se refiere a las concepciones donde al utilizar la palabra «sistema» se presupone que cabe usar este término en sentido no primordialmente metafórico para caracterizar al derecho (y a las estructuras sociales en general). En otros sitios he ofrecido explicaciones sobre lo básicamente engañosas que suelen ser las aproximaciones «sistémicas» para las ciencias sociales. Vid. Metodología jurídica irreverente [ref. supra: n. 6], 231-254 («La ilusión de venir a detectar unos “sistemas”)) y 325-327 (Suplemento); en Metodología (realista) del Derecho [ref. ibid.], estos sitios corresponden a las pp. 569 y 672-675; tales desarrollos fueron retomados también, con ciertas variantes en la presentación y unas ampliaciones, en E. P. HABA, Entre tecnócratas y «wishful thinkers». La visión «misionera» de las ciencias sociales, Granada, Comares, 2010, 76-98 («Ilusión, en las ciencias sociales, de proceder a detectar unos "sistemas"») y 111-112 (Supl.); mi versión inicial de esa crítica se encuentra en «Semiótica ilusionista y semiótica desencantadora», Doxa, núm. 23 (2000), 561-596 (allí esp. \$\$ 7-8:577 y ss.). Vid. también, por cuanto hace particularmente a la confusionista (¡y escapista!) metodología pergeñada por LUHMANN, las aforísticas observaciones que al respecto presento en «La opción capital...» [ref. supra: n. 4]: $\$ 2$ (allí la digresión: «Un ejemplo: La vertebral falta de referentes empíricos netos — bien diferenciables como tales- en los discursos del tipo "sistémico"-luhmanniano») y a la altura de las nn. 52-53. Tengo escrito un examen mucho más amplio sobre la falta de transparencia y el carácter mistificador de términos claves de dicha metodología, pero no sé si tendré oportunidad de llegarlo a publicar.

${ }^{21}$ Cfr. en alguno de los sitios siguientes: Rechtshteorie, 1996, Habermas Sonderheft, 279, n. 4; El espejismo... [ref. supra, n. 11], t. I., 26; Metodología (realista)... [ref. supra, n. 6], t. I, 90, a la altura de su n. 5. 
lingüístico de dar a entender que tal denominación implique inclusive una supuesta unicidad de «sistema».

EL «derecho» no existe — como fenómeno de dimensiones reales_ sino en tanto en cuanto tales o cuales cosas son llamadas así en las mentes de los locutores que «resuelven» al respecto y de quienes reciben sus efectos prácticos. Mas resulta que, en esas mentes, mucho de lo que se percibe como conforme al «derecho» según unos, se entiende como no-conforme a él según otros. Fuera de la innumerable y constantemente variada totalidad de todos esos «unos» más todos esos «otros», no hay «conforme» o «no-conforme», salvo ciertos trazos homónimos en el papel o los sonidos orales correspondientes. En definitiva: qué sea y qué no sea «conforme a derecho» —en el mundo social REAL - se determina según las variadas costumbres lingüísticas al respecto, entre las cuales hay también no pocas contradicciones. Cuando hay acuerdo sobre qué sea «conforme»... ipues lo hay! En las demás situaciones, para unos es «conforme» X (diferente de Z) y para otros lo es Z (diferente de X).

$* * *$

Si bien ATIENZA no irá, supongo, tan lejos como yo en la crítica a la idea de «sistema» jurídico (entiendo que, p. ej., se toma bien «en serio» los simplismos de DworKIN), me parece que en este extremo está más cerca de percibir la realidad que tú. Ello por cuanto él no deja de señalar: «yo no concibo al derecho simplemente (o fundamentalmente) como un sistema» (137 in fine, cursiva mía). En cambio, aun cuando no aclaras si los «límites» en que tú piensas conllevan que cuanto está dentro de esos «límites» constituya o no un «sistema» (ni en qué consistiría éste como tal), la circunstancia de que creas poder determinar semejantes «límites» hace que la puerta quede abierta a entender que sí puedan calzar ahí «adentro» unos aparatos de novelación conceptualista, como las disimulantes entelequias de LUHMANN o las de FERRAJOLI u otras imaginerías de ius-semánticas basadas en moldes de tipo «sistema». [Por cierto, ATIENZA no suscribe sin más lo de la mitología logicista formulada por ALEXY. Si bien, contrariamente a ti, Manolo ha señalado tener gran afinidad en general por las idealizaciones de este último autor, empero guarda la prudente reserva de no afiliarse a la estratagema de pseudociencia consistente en disfrazar los razonamientos de «ponderación» bajo ese espejismo de falsa precisión, el lanzado al presentarlos mediante unas supercherías de numerificación sistematizadora; más, él rechaza en general la pretensión de «algoritmo» para esos razonamientos (21 y ss.).].

También tú eres víctima, al parecer, de una cierta inocencia lingüística de ese tipo: presuponer que, necesariamente, $U N$ sustantivo $=U N$ contenido inequívoco propio (naturalismo lingüístico). Ya me he referido a tus palabras en cuanto a los «significados posibles» como «límite» para cuanto sea dable (según tú) entender «con propiedad» una «aplicación del derecho» (130). Por eso, si resulta que «de hecho» hay jueces que entiendan como «posibles» jurídicamente otros significados que los reconocidos como tales por ti, con respecto a unos casos jurídicos planteados, sostienes que esos intérpretes — vale decir, quienes no se atengan a lo que tú y quienes sean de tu misma opinión estimen que cabe aún dentro de los «significados posibles» ahí-: «NO están aplicando derecho», sino otras especies (no «jurídicas») de criterios. Dices:

Lo que sostengo es que cuando la regla que aplican contra la norma jurídica derrotada no está explicitada en otra norma jurídica que pueda hacerlo, los jueces no están aplican- 
do derecho (cursiva del autor), aunque desde el punto de vista moral, político, económico, etc., podamos considerar loable el comportamiento de ese juez jurídicamente desobediente (126).

Es verdad que abundan los contextos de comunicación donde puede ser inconfundible -intersubjetividad — qué se impute a alguno de esos sustantivos en especial — «derecho», «moral», etc.—y no sea dable imputarlo a otros de éstos. Pero no menos verdad es que en ciertos contextos de comunicación diferentes, ahí los contenidos asignados a unos y otros de estos términos se presentan entrelazados, se intersecan, sin que haya reglas lingüísticas consensuadas que determinen (intersubjetivamente) cuál de las distintas posibilidades siguientes sea aceptada por los locutores (ya sea todos éstos o una parte de ellos sí y otros no): ¿el significado X pertenece solamente al «sistema» A o pertenece solamente al «sistema» B o pertenece a ambos, o pertenece parcialmente (y cuáles «partes») tanto A como B, o...? Salvo cayendo en naturalismos lingüísticos como el de LUHMANN u otros esencialismos, y así también ése que parecieras sustentar incluso tú con respecto al término «derecho», la asignación de significados no puede dar cuenta sino de la existencia de usos lingüísticos REALES de la palabra en cuestión. Ninguno de éstos es ni más ni menos «posible» que los demás. TODOS esos usos dan en algún «verdadero» sentido usual de dicho término, por más contradictorios que algunos de ellos puedan ser entre sí. Y de ahí que, como con toda razón advierte ATIENZA: «...la noción de "interpretación posible", como en general la de "limite del derecho", que cada uno de nosotros tiene, NO sean del todo coincidentes» (138 in limine, cursivas mías).

Se puede considerar, desde luego, que unos usos sean más CONVENIENTES que otros. Mas eso no es simplemente una quaestio facti, sino que presupone una quaestio juris. Significa que en cuanto a esta cuestión se presenta como básica la pregunta clave que ni tú ni Manolo distinguen: ¿se trata, tal «conveniencia», de un juicio de valor categórico o de uno instrumental 22 ? Y en este último caso: ¿cuáles serían las pruebas, o al menos algunos buenos indicios, que acrediten la existencia de ciertos HECHOS (relativamente generales, o unos más bien particulares pero muy ilustrativos) que hicieren plausible — iinductivamente! — tal tesis valorativa?

Al parecer confundes una cuestión TERMINOLÓGICA, no menos multívoca que las palabras empleadas al respecto, con algo así como un sistema de reglas como el del ajedrez, o en todo caso con algo bastante aproximado a ello: la existencia de un universo lingüístico bien determinado como conjunto, netamente circunscrito en sus límites como tal, lo cual circunscribiría bien definidamente cuanto constituya EL juego «derecho» en general. En efecto, estás presuponiendo una hipotética firmeza de la distinción GENERAL entre «candidatos» positivos (los «posibles») y «candidatos» negativos (todos los «no posibles») a ser «piezas» de ese juego: el conformado por las normas que serían «propiamente» pertenecientes al Quid «derecho».

Tal vez tiene razón ATIENZA al advertir que: «Tiendes a considerar el derecho como un tipo de realidad semejante a lo que es un libro (en cuanto conjunto de enunciados y de significados)» (137, cursiva mía). También estás suponiendo, agrego yo, que todos los contenidos de ese libro puedan conformar algo así como un «sistema» de

22 Supra, n. 9. 
neta delimitación entre su «adentro» y su «afuera», como lo fantasea la terminología de LuHMANN. Con esto último concuerda también la afirmación tuya de que:

«el derecho es lo que está ahí afuera y nada más que lo que está ahí afuera y cualquiera puede ver». Mas NO lo sería, en cambio, lo señalado por «quien mantiene que también es derecho algo que está "más allá" de lo que ahí fuera todos vemos y, porque lo vemos todos, a todos nos ata por igual» (131 y ss., cursivas mías $)^{23}$.

A decir verdad, no me queda claro si lo afirmado en esta última transcripción entiendes sostenerlo tú mismo o si acaso lo invocas a modo de un ejemplo por el absurdo. Sea como fuere, lo cierto es que sólo con base en una afirmación semejante, o alguna bastante similar, es posible sostener, como al parecer piensas tú, que existe UN límite NETO entre lo que ES y lo que no es «derecho», aun a pesar de que «de hecho» unos (tú) y otros (así Manolo) «ven» tal límite ubicado en extremos que no coinciden entre sí.

Mal que le pese a la doctrina jurídica corriente, como también a metadoctrinas como la de LUHMANN, lo llamado «derecho» vigente en cada país no es UN sistema de lenguaje bien determinado, sino un conjunto en buena parte indeterminado (no sólo con vaguedades, sino inevitablemente lleno de «texturas abiertas») de juegos de lenguaje laxamente relacionados entre sí, muchos de los cuales son a su vez entendidos de distintas maneras -más o menos antinómicas - por sus operadores prácticos. Ese «límite» a que tú te refieres, no existe como $T A L$, ni siquiera semánticamente, si nos fijamos en las prácticas lingüísticas aplicadas ahí. Como tampoco son intersubjetivamente detectables como «límites» aquellas pautas, todavía muchísimo más vagas, que propone ATIENZA: «La vinculación del juez no es sólo a la letra de la ley, sino a sus razones subyacentes» (106, cursivas mías).

Pues sí, vuestra discusión sobre cuáles sean los criterios —unos u otros- bastante definidos (no digo que necesitarían serlo 100 por 100) para establecer «límites» entre lo que es y lo que no es «derecho» me parece vana, y por demás insoluble, en el plano teorético cognoscitivo propiamente. Mas en modo alguno dejo de reconocer que lo pensado como «límites» al respecto puede eventualmente producir unas consecuencias PRÁCTICAS, según qué CREA en tal sentido el operador jurídico llamado a resolver: «Situations that are defined as real...» (teorema de THOMAS). Según cuáles sean los axiomas definitorios que se manejen (ya sea expresa o implícitamente), y sobre todo en cuanto éstos fueren concebidos como definiciones «reales» ${ }^{24}$ (la presuposición más

23 Tómese en cuenta también la referencia que a las palabras iniciales de este pasaje efectúa ATIENZA [supra: a la altura de la n. 17].

${ }^{24}$ Cfr. G. R. Carrió, Notas sobre derecho y lenguaje, Buenos Aires, Abeledo-Perrot, 1965, 123-125 (puntos 4 y 5); allí con referencias a SAN Agustín, T. D. WELDON (The Vocabulary of Politics), H. KANTOROWICZ (The Definition of Law) y especialmente a la conocida obra Definition de R. ROBINSON) [ese librito, rotundamente excepcional frente a la carencia de tomar en cuenta unos conocimientos elementales sobre naturaleza del lenguaje en que suele incurrir la enorme mayoría de los estudios en teoría del derecho que dominan la escena de esta disciplina en la actualidad, después pasó a formar parte de una obra más extensa, que lleva el mismo título, donde se recogen también otros trabajos (de alto interés ellos también) pertenecientes al mismo autor; en su 3. " ed. (1986), el pasaje mencionado se encuentra en las 117-120]. Sobre las «definiciones reales» puede verse también Metodología (realista) del Derecho [ref. supra, n. 6], t. III: $\$ 51.3$ (503 y ss.) y Tema 8-Apéndice B.1 (566 y ss.). Dicho al margen: ¡cuánto más es dable aprender, en cuanto a la «lógica» real de discursos como los desempeñados por los operadores jurídicos (y también los de la política, la moral, la política, etc.), en exá- 
común), ellos conducirán a que la cabeza del locutor jurídico se oriente ya sea de unas o de otras maneras para «descubrir» —así lo piensa él— cuál es la solución jurídica «verdaderamente» correcta, esto es: entonces se cree saber qué dice «verdaderamente» la letra, cuáles son las razones «verdaderas», etcétera.

Así es cómo esa «verdad», ahí, viene a ser ni más ni menos que lo que cada locutor - y su grupo de afines - piense que es tal. Este orden de candideces viene impulsado, al menos en parte, por dichas creencias, poco importa lo fabuladoras que ellas sean (naturalismo lingüístico, esencialismos). Claro está, no puede haber datos empíricos susceptibles eventualmente de llevar a «falsar» semejantes ideas, una vez que son creídas. Esto por la sencilla razón de que, como en todo pensamiento esencialista, tales convicciones $N O$ dependen de percepciones capaces de falsar el tipo de «verdad» —INMANENTE, por definición— de esas formulaciones. Sólo sería dable «derrotarlas... de becho», si acaso...

\section{FUNDAMENTALES FALTAS DE DISTINCIÓN ENTRE LOS PLANOS DE ENFOQUE. LA IMPRONTA ESENCIALISTA}

Después de todo, mis reparos principales frente a vuestros planteamientos, en el fondo se sustentan en que esos modos (esencialismos, «novelas de conceptos», «fórmulas vacías», etc.) de encarar las cuestiones jurídicas hacen que, al fin de cuentas, no sea posible diferenciar bien QUÉ se procura indagar específicamente.

Para efectos prácticos, qué sea «derecho» se revela por datos de orden EMPÍRICO (tal como traté de aclararlo en el numeral anterior): son unos grupos de usos lingüísticos dados de modo efectivo. Pero es claro que, si de lo que se trata es de VALORAR unos u otros de tales contenidos discursivo-empíricos, el asunto no queda resuelto mediante dicha descripción simplemente. No digo que estos dos planos no hayan de combinarse entre sí. Más aún, reconozco que por lo general es necesario hacerlo, de unas u otras maneras, para tratar las cuestiones jurídicas. Lo que me importa subrayar, es que una cosa significa combinarlos, mas otra, muy distinta, no llegar a distinguirlos entre sí. Justificar tal in-distinción porque es cierto que ambas clases de elementos de juicio están «juntos» ahí, viene a ser algo así como, digamos, pensar que no vale la pena tomar el cuidado de medir por separado el ancho y la altura de una superficie, para calcular esta última.

En vuestra discusión, ambos planos suelen aparecer indiscriminados. Por ejemplo, cuando dices:

Yo no afirmo que de becho no sean las normas jurídicas derrotadas en la decisión de

los jueces a veces. [...] [No obstante:] Sencillamente, no ES derecho todo lo que de becho derrota a las normas jurídicas, ni siquiera todo lo que nos gusta que las derrote en tal o cual caso (126, cursivas mías).

¿De qué se trata ahí? Lo que estás entendiendo así por «normas jurídicas» o «derecho»: ¿es eso una descripción empírica de ciertos hechos lingüísticos (intersubjetiva-

menes como ése de CARRIÓ y en las advertencias generales básicas de VAZ FERREIRA [ref. infra: n. 32], que por tomarse «en serio» unas storytelling como las que están de moda hoy para los estudios en teoría del derecho! 
mente diferenciables de otros) o es una definición estipulativa o es una recomendación semántica (ya sea intersubjetivamente manejable o es más bien intuitivo-personal) o es un criterio contrafáctico de valoración o es...? ¿O será que, también para ti (como, al parecer, para ATIENZA), carece de importancia - tanto teoréticamente como para la práctica jurídica - tomar en consideración tales diferenciaciones? [Aclaro: no pretendo afirmar que sea indispensable efectuar todas esas distinciones o algunas de ellas, y aun otras, para examinar atinadamente toda cuestión de las ciencias sociales, ni siquiera entre las de orden jurídico; pero considero que a menudo sí lo es, especialmente para las que suelen plantearse en teoría del derecho (lo es, justamente, para «desindiscriminar» aspectos cruciales de vuestra controversia como los señalados en mi Comentario anterior y aquí mismo).]

Pues sí, lo de elevar la discusión hacia el nivel de unos supuestos criterios GENERALES unívocos para resolver tales cuestiones es lanzarse a buscar alguna cuadratura del círculo bajo ese nombre, «derecho», y tanto más si acaso uno cree que hasta haya logrado encontrarla. Tal parece ser el caso por parte de ustedes dos, aunque el cuadrado de uno no coincida con el del otro. Pero no, no existen ni pueden llegar a existir criterios para dirimir que sea $E L$ «derecho» en general. Únicamente se llegan a conformar numerosos criterios «locales» (por así decir) que constituyen, respectivamente, ciertos consensos efectivamente en vigor — iprovisoriamente! — con respecto a tipos ESPECÍFICOS de problemas jurídicos, de generalidad limitada. En cambio, no sólo Manolo sino también tú terminan cayendo en unos esencialismos ${ }^{25}$ acerca de qué es «derecho», como ya tuve oportunidad de adelantarme a decir en el numeral anterior.

Al parecer, has confundido una determinación que es antes que nada (jaunque no exclusivamente!) TERMINOLÓGICA — convencional, pues- con algo así como una determinación ONTOLÓGICA. Retomo tus palabras: «Sencillamente, no ES [¿empíricamente u «ontológicamente»?] derecho todo lo que de becho derrota a las normas jurídicas...». ¿Qué entiendes significar ahí con el término «es»? ¿Quieres tal vez decir que eso es obviamente, palmariamente, indudablemente... reconocible ASÍ, por «esencia» o algo por el estilo? O bien, ¿de qué otra manera sería reconocible ello mismo? ¿Será que de veras existen unas pautas de reconocimiento indubitables, evidentes sin más («esencias» o lo que fuere), para reconocer qué sentido inmanente tiene cada norma o conjunto de éstas — no sólo si hay consenso al respecto, sino aun si NO lo hay entre los propios juristas—?

$$
* * *
$$

Al parecer, tú estás dispuesto a contestar afirmativamente esa última pregunta [conforme a los pasajes tuyos $\left(130^{26}\right.$ y $\left.126^{27}\right)$, transcritos más atrás acerca de en dónde residirían los «límites»]. Vale decir que, según tú, los sentidos lingüísticos «posibles» que reciba la palabra «derecho» no se determinarían mediante ciertas contingentes CONVENCIONES (más bien tácitas casi siempre) de usos de la palabra en cuestión; los cuales pueden ser, no sólo bastante indeterminados en parte, sino inclusive antinómi-

${ }_{25}$ Cfr. Metodología jurídica irreverente [ref. supra, n. 6], 204-211 («Esencialismo»); o Metodología (realista)... [ref. ibid.], 450-459 y 531; un examen mucho más amplio al respecto es el Tema 8 (Esencialismo y «naturalezas jurídicas») presentado en el t. III (CD) de esta última obra.

26 Supra: $\$ 5$ in fine.

27 Supra: en el presente numeral. 
cos unos frente a otros. Si fuera como señalas tú, habría algún METAcartabón, SUPRAempírico —vale decir: ¡no «derrotable» en sí mismo por «hechos»! — cuyo conocimiento permitiría saber cuáles entre los usos que tiene «de becho» ese término son los que cuajan con el verdadero «ES» de él mismo, y cuáles NO.

La diferencia clave entre lo que piensas tú y lo que cree ATIENZA sobre qué ENTRA, y qué no entra, dentro de la gran esfera semántica «propiamente» de la palabra «derecho» consistiría, pues, en que tú sí sabes cómo identificar netamente ese ES: qué significados son «propiamente», de veras, «posibles» como «derecho» en relación con determinada cuestión jurídica. Mientras que, según tú, Manolo no se referiría a ese ES propio, sino a unos elementos de juicio que no pertenecen realmente al ES de dicho término; estos elementos constituirían antes bien atributos propios de otros ES, ajenos a cuanto conforma propiamente el área de significados de la palabra «derecho». Ergo: aquellos juristas que conocen de veras ese «es», ellos sí saben a ciencia cierta que tales o cuales significados NO son «posibles» jurídicamente, a pesar de que no falten juristas (p. ej., Manolo) que los aceptan como bien «posibles» ahí.

Si es verdad esto que señalas tú, los significados «posibles» serían, pues, unos sentidos necesariamente inmanentes (llámeseles o no «esencia») a la propia palabra «derecho», fijados por ésta misma, digan lo que digan los «hechos» discursivos —así cualesquiera eventuales «derrotas» de esos significados - desempeñados por alguna parte de los propios juristas al utilizar esa palabra. Puesto que, según tú, ciertos significados que los jueces imputan «de hecho» a ciertas normas NO son «posibles» como entendimiento de ellas mismas, los verdaderamente «posibles» en tal sentido no serían sino OTROS significados entre cuantos se dan de hecho. Serían estos últimos sentidos, ¡nada más ellos mismos!, lo capaz de establecer y revelar «propiamente» cuál es la frontera verdadera («límites») entre: a) los usos de becho que sí se ajustan al ES de la palabra «derecho» (esos que sabes identificar tú); b) cualesquiera otros usos de becho que llegue a recibir esa palabra (p. ej., unos que está convencido de poder identificar Manolo), frente a los cuales dicho «es» se mantiene inmune (como toda esencia) por más que sea «derrotado» en la realidad social.

Así terminas avalando tú también, quiéraslo o no, la legitimidad intelectual de recurrir a unas peculiares «intuiciones» (por así llamarles) lingüísticas acerca de qué es y qué no es «derecho». Digo peculiares, aunque no sean exclusivamente tuyas, pues no son testables por vías de conocimiento empírico-intersubjetivas acerca de cuáles son los usos lingüísticos efectivos aplicados ahí; habrá juristas que compartan intuiciones lingüísticas como las tuyas, otros no. En todo caso, ellas no son controlables en grado mayor que la inefable «racionalidad» y demás a que se remite ATIENZA. En ambas posiciones, por más que sus enunciaciones se contraponen semánticamente, esta contraposición queda basada en lo que cada cual cree poder reconocer respectivamente como esencia de $E L$ «derecho», sean cuales fueren los multiformes y en buena medida antinómicos usos que «de hecho» (lo dices tú mismo) recibe o pueda recibir esta tan lábil etiqueta lingüística.

Pero, ¿no será que no son ustedes, sino antes bien yo quien confunde los planos de examen? No sé si considerarías del caso replicarme así, más o menos: «El "es” a que 
yo [i. e., tú] entiendo referirme, no es del tipo quaestio facti sino una quaestio juris. Por tanto, nada más lógico que reconocer que tal «es» no pueda ser «derrotado» más que «de hecho», pero jamás experimentará «derrotas» que sean «propiamente» de «derecho» [las entrecomilladas son formulaciones literalmente tuyas]». Desde luego, así resulta imposible —ipor definición! — que tal postulado fuera acaso puesto en jaque ni siquiera en caso de ser distintas, o hasta contrarias, cualesquiera prácticas lingüísticas que de hecho desempeñen muchos o pocos locutores, sean éstos cuales fueren, y ni aun en caso de que éstos últimos son reconocidos como juristas profesionales en el ejercicio de tales desempeños.

En efecto, ni la afirmación de esencias ni los juicios de valor categóricos son cuestionables en razón de bechos producidos. Si uno o muchos hechos no se corresponden con la esencia «percibida» por sus creyentes o con tales juicios de valor... ¡tanto peor para los «hechos»! Quiere decir, lo reconozco, que mi propia argumentación (la presentada hasta aquí) es pertinente sólo en la medida en que el «es» que tú planteas fuera susceptible de ser sometido a procedimientos de falsación empírica, al menos en parte; vale decir, haciéndolo mediante unos niveles de examen dirigidos a verificar ciertas quaestio facti que se esté dispuesto a reconocer como DECISIVAS al respecto. Esto último bien cabe cuando estamos ante unos juicios de valor que se entienden como INSTRUMENTALES; no así, claro está, ante unos juicios de valor vistos como categóricos (si bien estos últimos intervienen aun en el seno de aquéllos, en calidad de bases últimas) ${ }^{28}$. Quiere decir que, únicamente si afirmaciones como las tuyas o las de Manolo NO se entienden como una «pura» quaestio juris, y por añadidura asumida como juicio de valor categórico, sólo entonces habría algo para «testar», aun si esto consista en unas regularidades discursivas (partiendo de la base de que éstas han de ser empíricamente comprobables). Ahora bien, ¿cuáles podrían ser esos «algo»?

Para que fuera viable cierto control empírico, en cuanto al «es» que afirmas, tendrías que estar en condiciones de mostrar la existencia de criterios intersubjetivamente reconocidos en el gremio de los juristas en cuanto a «re-conocer» en forma indubitable (o poco menos) qué «es» derecho y qué no lo «es», cuando las respuestas jurídicas al respecto proporcionadas por unos de aquéllos se contradicen con las de otros dentro del círculo de locutores jurídicos considerado. Dudo mucho que a tu alcance, ni al de nadie, esté la posibilidad de exhibir tales patrones INTERSUBJETIVOS —o sea, a modo de «es»— tratándose de los conflictos de interpretación «vivientes» en las prácticas judiciales (...en caso de que sí puedas, jadelante!). Aunque yo simpatizo más con contenidos que asignas a tu «es» que con las maneras cómo asigna otros ATIENZA, no puedo dejar de reconocer que los tuyos son no menos lingüísticamente «opinables» que los de Manolo, vale decir, tan «significados posibles» los unos como los otros. En cuanto, al parecer, tú no estás dispuesto a reconocer esto último, vuestro debate queda planteado, en definitiva, entre dos esencialismos: el tuyo y el de él, cuyos respectivos «es» lingüísticos pueden llevar a inferencias prácticas dispares frente a casos concretos dados. Muy bien lo ejemplifican, justamente, esos casos invocados por ustedes. Un esencialismo linguo-naturalista (por tu lado) frente a un esencialismo axiológicocognitivista (por el lado de Manolo).

28 Sobre la crucial diferencia entre estas dos categorías fundamentales de juicios valorativos, $c f r$. los sitios ya mencionados en la n. 9. 


\section{0. ¿CÓMO CONOCER LOS «LÍMITES» DEL «DERECHO» POSITIVO? [III]: APROXIMACIÓN REALISTA ANTE ESA CUESTIÓN}

El reconocimiento de unos «límites» para lo que en un medio social se considere «derecho», en la medida en que un intérprete jurídico crea sinceramente en ellos, éstos no pueden ser otros que aquellos que los procesos de aprendizaje de su propia socialización lingüística (la académica y la extraacadémica) han introyectado en la mente personal de ese jurista, así como en las de muchos otros colegas suyos... imas no en todos estos por igual! [Eso sí, entiendo referirme a lo que en otro sitio he llamado las interpretaciones jurídicas de «buena fe», esto es, solamente cuando este intérprete mismo cree de veras lo que está afirmando (y, por supuesto, no estoy pensando en deficientes mentales, ni en personas desconocedoras del idioma o de la especialidad en juego, u otras circunstancias por el estilo). Es ése el caso normal en las discrepancias entre juristas. No por ello niego que también pueden tomar la palabra ahí unos intérpretes de «mala fe»: el abogado que alega «cualquier cosa» en favor de su cliente, el juez «presionado», etc.; mas no es tal tipo de situaciones lo que examino aquí, ni creo que sea lo encarado en el debate entre vosotros ${ }^{29}$.]

No niego, por cierto, que la semántica del derecho es una «realidad», pero ella es principalmente de orden mental: consiste en los proteicos conjuntos de ideas - que abarcan tanto múltiples coincidencias como múltiples discrepancias al respecto- que son PENSADOS como «derecho», por unos y otros locutores, en infinitas variedades de contextos. En todo ello abundan las regularidades, pero también caben muchas IRregularidades (si bien son menos éstas que aquéllas), en planos semánticos y en los de las pragmáticas lingüísticas correspondientes. De ahí que sólo en unos sentidos metafóricos, o en todo caso no poco indeterminados para establecer sus contenidos específicos, puede decirse que ESO constituya algo así como un «sistema» ${ }^{30}$, o sea como fuere algo bien distintamente fijado de manera global. Nunca de antemano, sino únicamente en virtud de comprobaciones prácticas a posteriori es dable detectar cuáles sean las regularidades y cuáles las irregularidades en el uso de los discursos jurídicos («límites» y demás), pero siempre de manera que no puede ser sino provisional.

Nada de lo señalado quita que semejantes «límites» no suelen depender de algo así como unos caprichos personales de cada operador jurídico. Se trata más o menos de unos extremos que el intérprete considerado asimila porque los manejan también aquellos grupos de locutores con los cuales su pensamiento profesional se identifica. Todos o la mayor parte de los operadores de unos juegos lingüísticos llamados «derecho», en un país, coinciden habitualmente en reconocer tales o cuales «límites» para muchísimos usos de este término. Pero no menos real es que esos locutores vienen también a no coincidir al respecto, para grupos significativos de ellos mismos ${ }^{31}$, en cuanto a otros usos lingüísticos de los manejados en sus discursos jurídicos. De ahí que tanto tú como Manolo estarán de acuerdo en cuanto a UNOS «límites», pero NO en cuanto

29 Para la distinción entre ambas clases de intérpretes, cfr. E. P. HABA, Tratado básico de derechos bumanos, t. I (Conceptos fundamentales), San José (C. R.), Juricentro, \$18.III, 1986 («interpretaciones creíbles e intérpretes de "mala fe"»: 268 y ss.).

30 Vid. los sitios indicados supra, n. 20.

31 Es lo que sucede, tan comúnmente, cuando la discrepancia se produce entre juristas «de buena fe» [supra, a la altura de la n. 29]. 
a otros, frente a casos dados [cfr. las líneas de ATIENZA (138 in limine) recogidas más atrás: $\$ 4$ in fine].

Las discrepancias efectivas aparecen diluidas al encararlas como susceptibles de resolver en los «cielos» semánticos de unas afirmaciones de principio generalísimas, pues al presentarse ellas de semejante manera no pueden sino ser de lo más ubicuas. Sus verdaderos alcances no van a ponerse claramente de manifiesto sino en usos CONCRETOS de los términos en cuestión, tal como ocurre en vuestra discusión acerca de esos casos judiciales. En efecto, las discusiones sobre qué ES «derecho» no tocan «tierra» sino en cuanto se examinan tales o cuales problemas específicos. Entonces nos encontramos con que los criterios al respecto empleados para responder a unas cuestiones jurídicas específicas difieren de los empleados para otras; incluso puede pasar, como en vuestra disputa, que tales desacuerdos lleguen hasta a versar sobre si algunos de esos criterios son o no son «propiamente» del «derecho» positivo para lo examinado ahí — «propiamente», esto es: como si eso pudiera depender de algún criterio absolutamente definido con aplicación todo-general (¡ilusión de geometrismo!) en la materia-.

Si nuestros exámenes no hacen «rancho aparte» con respecto a cómo los discursos jurídicos funcionan en la práctica, la pregunta acerca de qué «es» derecho no será susceptible de ser contestada sino mediante un señalamiento esencialmente tautológico: «derecho» ES todo lo que ES «derecho». Este «es» no puede significar, realísticamente, ni más ni menos que lo siguiente: «derecho» es cuanto sea visto, ¡de hecho!, como «derecho», por parte de unos u otros grupos de locutores de carne y bueso. Y si se quiere restringir un tanto esta generalidad absoluta, podría estipularse que, para efectos de identificar la actividad jurídica profesional, los sujetos tomados en consideración como capaces de «ver» ESO son grupos significativos de quienes desempeñan tal actividad especial. Mas aun así no habrá más remedio que registrar tanto acuerdos como desacuerdos entre éstos mismos, cuando sea cuestión de aplicar ese término a unas u otras cuestiones prácticas realmente discutidas en los tribunales. En este último caso, cada grupo de quienes se pronuncian contradictoriamente al respecto identifica a $S U$ propio modo cuáles sean los contenidos de la categoría «jurídico». De modo tal que, en los hechos, tan «derecho» es lo señalado por unos como lo señalado por otros de esos locutores; surgen ahí contradicciones análogas a tantas de las que son bien frecuentes también en los usos de muchos otros términos. Significa que, en definitiva, la búsqueda de una definición GENERAL unívoca de qué «es» derecho carece de toda importancia práctica — aun en el muy (ipero muy!) hipotético caso de que pudiera encontrarse tal definición sin que consista en una fórmula vacía, o poco menos-.

\section{A MODO DE CONCLUSIÓN: PRESENCIA DE UNOS ELEMENTOS DE REALISMO, PERO SECUNDARIOS Y DE CONFIGURACIÓN IMPRECISA, EN MEDIO DE LA PSEUDO-OBJETIVIDAD DISIMULADORA EN QUE CONSISTEN LAS SIBILINAS FÓRMULAS LLAMADAS «PONDERACIÓN»}

Para concluir, y con independencia de los detalles (muchos de ellos iluminadores, esencialismos aparte) sobre los cuales se centra vuestra discusión, me tomaré la libertad de señalarte aforísticamente mi propia opinión sobre modelos de razonamiento- 
«ponderación» como los propugnados por ALEXY y ATIENZA. Esa opinión mía debe mucho a los estudios tuyos sobre eso, inclusive este último, mas tengo la impresión de que ella no se agota en lo señalado por ti. Creo haber logrado emanciparme de modo más radical que tú de toda concesión a considerar el asunto principalmente en unos planos que nada más (o sobre todo) son apenas INMANENTES — i. e., unas u otras «novelaciones» teoréticas - a cómo funcionan las aproximaciones más habituales acerca de las cuestiones jurídico-doctrinarias: o sea, el centrarse en tratar sobre éstas mediante elucidaciones anidadas principalmente en tal o cual «cielo de los conceptos».

Mas no por eso dejo de reconocer que, aun en medio de toda su neblinante fanfarria de instrumentos conceptuales en claves de falsa precisión ${ }^{32}$, esos pedantes expedientes de formuleríos denominados «ponderación» contienen también un ingrediente de realismo, el cual no suele hacerse presente en el razonamiento doctrinario sobre las cuestiones jurídicas de «principios». Si bien se mira, es de advertir que el llamado principio de «idoneidad» no es otra cosa que un juicio de valor instrumental, racionalidad de medios (empíricos) con arreglo a fines (postulados axiomáticamente). Sólo que ahí ello aparece introducido sin presentarlo de la franca manera en que supo formularlo WEBER ${ }^{33}$, y en definitiva ocupa entonces un lugar secundario en medio de aquel despliegue de procedimientos de contenido ambiguo. Esto último, lo del contenido ambiguo y al fin de cuentas DECISIONISTA, es lo que tú has sabido poner netamente sobre el tapete, una y otra vez, en tus estudios sobre la «ponderación» judicial.

Ahora bien, Manolo señala que «ALEXY nos muestra cuáles son los lugares, los TÓPICOS, a los que hay que acudir para resolver conflictos entre derechos o entre bienes» (22 in limine, cursiva mía). Quiere decir, me parece, que al fin de cuentas se trataría sobre todo de lo que BERNAL PULIDO ha caracterizado así:

la ponderación $N O$ es un procedimiento algorítimico que por sí mismo garantice la obtención de una única respuesta correcta en todos los casos, [...] Si bien no puede reducir la subjetividad del intérprete, en ella [i.e., la ponderación] sí puede fijarse cuál es el espacio en donde yace esta subjetividad, cuál es el margen para las valoraciones del juez y cómo dichas valoraciones constituyen también un elemento para fundamentar las decisiones. [...] La gradación de la afectación de los principios, la determinación de su peso (¿matemático?) abstracto y de la certeza de las premisas empíricas y la elección de la carga de la argumentación apropiada para el caso, conforman el campo en el que se mueve dicha subjetividad ${ }^{34}$.

Si hago abstracción de la cuestión del «peso», salvo que este término se entienda en un sentido solamente metafórico, yo no tendría mayor cosa que objetar sustancialmente a tal propósito, aparte la inusitada pedantería — superflua, confusionista: ¡falsa precisión! - con que ALEXY presenta tales «tópicos» o «espacios». Lo más engañador es que ello se invoca como si todo eso respondiera a un sistema propiamente dicho (sea o no que se lo presente mediante esta última palabra), señaladamente por ser objeto de unas presentaciones pseudo-«objetivas» mediante el recurso al ocultamiento detrás de ciertas disimulaciones formuladas mediante unas engañifas algebraicas y numerificadoras.

32 Cfr. C. Vaz Ferreira, Lógica viva, Montevideo, Obras de Carlos Vaz Ferreira. Homenaje de la Cámara de Representantes de la República Oriental del Uruguay, vol. IV, 1963 [ed. or. 1910; hay también eds. en Losada, Buenos Aires], cap. «La falsa precisión».

33 Cfr. los sitios indicados en la n. 9 (supra).

34 C. Bernal Pulido, «Estructura y límites de la ponderación», Doxa, núm. 26, 2003, 225-238, § V (238, cursivas mías). 
Si de lo que se tratara fuese apenas de señalar unas opcionalidades como tales, desde luego que bien podría hacerse sin recurrir a semejantes artificios de presentación. En el libro de EsSER sobre los principios jurídicos, por ejemplo, las opcionalidades al respecto son exhibidas de una manera infinitamente más rica, y por cierto sin la «mentirilla» de dar a entender que su tratamiento pueda ser objeto de un procedimiento estandarizado y relativamente seguro en cuanto a determinar UNA SOLA solución como netamente más aceptable que tantas otras posibles, en todos o la gran mayoría de los casos donde se invocan «principios».

Recurrir a principios jurídicos y calibrarlos entre sí —optar entre ellos, graduarlos en sus aplicaciones, someter todo eso a razones - es necesario, desde luego, para resolver ciertas cuestiones de derecho. Mas para proceder a ello, eso que tienen necesidad de efectuar los jueces en tales circunstancias, en modo alguno hace falta complicarles la vida sometiéndolos al crucigrama de presentarlo bajo un formulerío como el propugnado por ALEXY. No menos cuando se recurre a unos u otros crucigramas para efectos de presentación (disimuladora) de la fundamentación oficial de su resolución, lo cierto es que se trata de una decisión tomada en virtud de preferencias ideológicas o doctrinarias del propio juez. No digo que esas preferencias sean simplemente «caprichosas», o algo por el estilo, pues no menos cierto es que ellas están de acuerdo con preferencias similares de muchas otras personas, dentro y fuera del gremio de los juristas profesionales. Justamente tal acuerdo, el del amplio grupo de personas que también piensan así por haber asimilado una respectiva formación mental similar, es lo que otorga, respectivamente tanto a quienes hagan prevalecer cierta interpretación jurídica basándola en determinados principios como a quienes hagan prevalecer otra interpretando esos mismos principios de manera distinta o recurriendo a principios diferentes, la sensación mental de «objetividad» al respecto. Como no es un sólo jurista, sino muchos entre ellos quienes piensan de esa misma manera, la escogida a su vez por el juez «ponderante», éste queda plenamente convencido de la «objetividad» de su propio razonamiento.

El hecho de que acaso otros jueces, y seguramente muchos otros juristas, crean no menos «objetivamente» (a juicio de ellos mismos) en que ahí la «verdadera» respuesta de derecho no es aquélla (p. ej., la tuya) sino alguna muy diferente (p. ej., la de Manolo) no inquieta ni a los unos ni a los otros, pues todos ellos por igual cultivan la Superstición del Único Significado Verdadero. Al someterse a los vericuetos formulistas de «ponderación» para presentar las elecciones interpretativas hacia las cuales se incline quien adopta la resolución final, se saca fuera de foco el hecho de ser ellas jurídicamente optativas; así es como esto último puede quedar oculto hasta ante los ojos del propio juez escogente, quien de tal modo se brinda a sí mismo la «buena conciencia» de resolver como mero técnico el asunto en disputa. No pudiendo haber, pre-supuestamente, sino una sola manera «correcta» de organizar los principios jurídicos concernientes al asunto discutido, es obvio que esa manera no puede ser a los ojos de cada jurista, respectivamente, sino la entendida como tal por él mismo (junto con quienes piensen de la misma manera).

Claro que si los locutores jurídicos estuvieran al tanto de ciertos muy elementales conocimientos sobre cómo funcionan realmente las dinámicas lingüísticas (vale decir, poseer unos conocimientos como de «contra-retórica» y tener siempre muy atenta la 
mirada a las dimensiones pragmáticas de sus conceptuaciones), tal vez no caerían tan fácilmente en tales candideces. Mas esto último no es sino una posibilidad muy remota. No calza, ni poco ni mucho, con los adiestramientos intelectuales (esencialmente ius-noveleriles) más firmemente introyectados en los juristas. La storytelling llamada «ponderación» no hace sino poner eso de manifiesto una vez más; sólo que lo hace de manera máximamente artificiosa.

Para numerosas cuestiones jurídicas es inevitable, claro está, que los razonamientos desempeñados por los juristas recurran a unos u otros principios de derecho ${ }^{35}$. Pero la verdad es que sin prescindir de tomar importantemente en cuenta tales o cuales principios jurídicos, bien pueden ser puestos sobre la mesa judicial en formas mucho menos complicadas - y por cierto libres de tanta disimulación formulista- que lo de embarcarse en esa peculiar «máquina de-partir-cabellos» (Haarspaltemaschine —JHERING-) denominada ponderación.

$$
* * *
$$

Bueno, aquí pongo stop. El asunto da para más, claro está, pero nadie me reprochará «frenarme» en cuanto a la posibilidad de añadir todavía otras cuantas precisiones. Es muy posible que, como dice Manolo: «...la discusión sobre la ponderación —a pesar de la enorme cantidad de páginas que ya se han escrito sobre el asunto- no ha hecho, por así decirlo, más que empezar» (87). En efecto, la cantidad de páginas por añadir promete multiplicar ponencialmente lo «enorme» que ella es ya, máxime habida cuenta de que seguramente va a proseguir por el derrotero que ha transitado hasta ahora, el de pasar por encima ( imás vale no meneallo...!) de interrogantes como aquéllos hacia los cuales he tratado de dirigir la atención aquí. Sólo que, eso sí, la larga vida que él le augura no creo que lleve, después de todo, a advertir nada sustancial que no hayan tenido ya la perspicacia de señalar ustedes dos, más que suficientemente. Si es cuestión de seguir eludiendo tales interrogantes, debiera bastar y sobrar, digo yo, con este vuestro debate tan minucioso sobre las sutiles tramas que esa especial «novela de conceptos» está en condiciones de hacer jugar en el seno de los discursos jurídicos. Y no hay cuidado... ¡mis sugerencias al respecto caerán en el vacío!*.

35 Para el examen analítico de los multifacéticos grandes tipos de usos que el término «principios» recibe en los discursos jurídicos, poniéndolos de manifiesto con base también en (y referencias a) literatura especializada internacional existente desde mucho tiempo atrás sobre ese tema, vid. E. P. HABA y J. F. BARTH, Los principios generales del derecho, según la doctrina internacional y en los tribunales costarricenses, San José (C. R.), Investigaciones Jurídicas, 2004 (www.libreriaucr.com/catalogo/). El contenido de la Primera Parte de esa obra se encuentra también, en versión algo más amplia, en Metodología (realista) del Derecho [ref. infra, n. 19], t. III: Tema 7 («Los principios generales y las fuentes del derecho»).

*enriquepedrobaba@gmail.com o ehaba@ice.co.croenrique.haba@ucr.ac.cr.. 